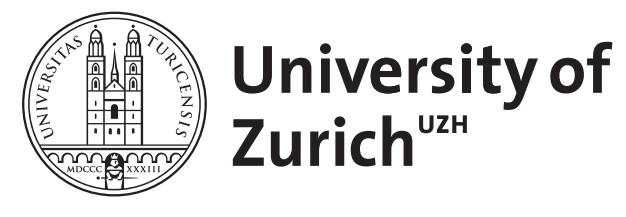

\title{
What drives China's current account?
}

\author{
Hoffmann, Mathias
}

\begin{abstract}
The paper offers an empirical taxonomy of the factors driving China's current account. A simple present-value model with non-tradeable goods explains more than 70 percent of current account variability over the period 1982-2007, including the persistent surpluses since 2001. It also correctly predicts the decline of China's current account since 2008. Expected increases in the prices of non-tradeables (e.g. housing and medical care) and expected declines in net output (GDP less investment and government spending) are the main channels of external adjustment. Much of China's current account surplus seems driven by shocks that have global effects by persistently depressing the world real interest rate. This is consistent with recent theoretical models that suggest that factors related to China's domestic financial development are key in understanding global imbalances.
\end{abstract}

DOI: https://doi.org/10.1016/j.jimonfin.2012.07.005

Posted at the Zurich Open Repository and Archive, University of Zurich ZORA URL: https://doi.org/10.5167/uzh-92486

Journal Article

Accepted Version

Originally published at:

Hoffmann, Mathias (2013). What drives China's current account? Journal of International Money and Finance, 32:856-883.

DOI: https://doi.org/10.1016/j.jimonfin.2012.07.005 


\title{
What drives China's Current Account?*
}

\author{
Mathias Hoffmann ${ }^{\dagger}$
}

This version: July 2012 .

\begin{abstract}
The paper offers an empirical taxonomy of the factors driving China's current account. A simple present-value model with non-tradeable goods explains more than 70 percent of current account variability over the period 1982-2007, including the persistent surpluses since 2001. It also correctly predicts the decline of China's current account since 2008. Expected increases in the prices of non-tradeables (e.g. housing and medical care) and expected declines in net output (GDP less investment and government spending) are the main channels of external adjustment. Much of China's current account surplus seems driven by shocks that have global effects by persistently depressing the world real interest rate. This is consistent with recent theoretical models that suggest that factors related to China's domestic financial development are key in understanding global imbalances.
\end{abstract}

JEL CLASSIFICATION: F32, F30, F40

KEYWORDS: China, Current Account, Present-Value Models, External Adjustment, Global Imbalances, Savings Glut, Financial Frictions

${ }^{*}$ This research was begun while the author was a visiting fellow at the Hong Kong Institute of Monetary Research (HKIMR). I would like to thank the HKIMR for its wonderful hospitality and support. For comments and suggestions, I am grateful to Joshua Aizenman, two anonymous referees, Hongyi Chen, Yin-Wong Cheung, Dong He, Hans Genberg, Pierre-Olivier Gourinchas, Wei Liao, and Zhiwei Zhang. The paper has also benefited from the insights of seminar participants at Hong Kong Monetary Authority, Hong Kong University of Science and Technology, University of Tokyo, the meetings of the committee on macroeconomics of the Verein fuer Socialpolitik, the NBER Summer Institute, Bundesbank Workshop on Money and Finance in East Asia, the HKIMR Conference on the Chinese Economy and the CESifo Macro and International Finance Conference.

†University of Zurich, Department of Economics, Chair of International Trade and Finance, Zuerichbergstrasse 14, CH-8032 Zurich, Switzerland.

E-Mail: mathias.hoffmann@econ.uzh.ch Web: www.econ.uzh.ch/itf 


\section{Introduction}

China's persistent current account surplus has attracted considerable academic and public attention in the last years. It is often regarded as one of the main sources of a perceived imbalance in global capital flows and as the mirror image of the persistent U.S. trade deficit.

While a range of explanations have been discussed for China's surplus, surprisingly few attempts have been made to assess the relative merit of different mechanisms of China's external adjustment in a simple, unified theoretical framework. ${ }^{1}$ This is what I seek to do in this paper. As the base of my empirical analysis, I use a simple intertemporal model of the current account with non-tradeable goods in the mold of Bergin and Sheffrin (2000). The model nests four basic channels of external adjustment: i) consumption smoothing, ii) net factor income payments, iii) consumption tilting due to expected changes in the world real interest rate and iv) consumption-tilting due to expected changes in the real exchange rate.

The main results can be summarized as follows: first, the simple model can explain more than 70 percent of the variation in China's current account over the period since 1982. It also explains most of the run-up in the Chinese current account surplus since the beginning of the 2000s and also correctly predicts the recent decline of China's current account surplus out-of-sample. This result may in itself be surprising since it is probably fair to summarize the tenor of the recent debate as implying that the textbook model (see e.g. Obstfeld and Rogoff (1995), ch. 2) would not fit China's recent experience. Turning to the channels of external adjustment, I identify consumption tilting due to expected rises in the relative price of non-tradeable goods and consumption smoothing (expected declines in net output growth) as the key factors. Net factor income plays only a negligible role

\footnotetext{
${ }^{1}$ See e.g. Gruber and Kamin (2007) for a panel study of Asian surpluses.
} 
whereas expected changes in the world interest rate are negatively correlated with China's current account.

I assess the robustness of my conclusions to various changes in the definition of China's external surplus and the definition of the real exchange rate. Some recent analyses have emphasized the role of trade mis-invoicing and measurement error in China's current account balance (see Lane and Milesi-Ferretti (2007), Zhang (2008)). To assess the importance of these issues for my conclusions, I also present results based on alternative calculations of China's external balance based on Zhang (2008). These changes do not affect the main result though: the model still replicates most of the variability in China's current account patterns, including the run-up of surpluses in the last couple of years.

How can these findings be interpreted? First, at a general level, it is surprising that a simple intertemporal model seems to fit some key aspects of the data so well. This would seem to be at odds with the bulk of the literature that has emphasized the importance of various frictions for the explanation of why capital tends to flow uphill, i.e. from major emerging markets to developed economies, primarily the US (see e.g. Caballero, Farhi and Gourinchas (2008), Mendoza, Quadrini and Rios-Rull (2009) and Song, Storesletten and Zilibotti (2011)). Domestic financial frictions, the presence of capital controls and the controlled exchange rate regime would a priori seem to violate the assumptions of the simple intertemporal model of the current account concerning international capital mobility. Furthermore, the size of China's economy invalidates the usually maintained assumption of a small open economy that is a price taker in world capital markets. I make the following remarks: first, the empirical analysis in the paper is based mainly on the log-linearization of an intertemporal budget constraint which, by itself, does not rest on particular theoretical assumptions about capital mobility or the impact of Chinese savings on world interest rates. The baseline intertemporal model of the current account essentially restricts this budget constraint only through the consumption Euler equation. In my theoretical setup below, I therefore also introduce a savings friction which drives a 
wedge between domestic and international interest rates and therefore also impacts on the consumption-Euler equation. As recently argued by Gourinchas and Jeanne (2009), such savings wedges (rather than frictions in capital accumulation) appear as prime candidates in explaining why emerging economies such as China run large current account surpluses. I show that - as long as the savings wedge is constant - the base-line log-linearized setup of my model remains unaffected vis-à-vis the setup without restrictions to capital mobility. It is therefore an empirical question to what extent the maintained assumption concerning time-invariant financial frictions is supported by the data. My findings suggest that the model fits the data surprisingly well - at least when compared to some of the most empirically successful incarnations of the model on data of highly financially integrated, developed economies. While the model is much too parsimonious to single out a specific theoretical mechanism as a driver of China's current account, it provides a useful vehicle to collect and structure a set of stylized facts which can then be confronted with the empirical implications of various mechanisms that have been discussed in the theoretical literature. In this respect, my approach follows a a successful recent strand of the literature on emerging market macroeconomics that has argued that stylized models fit the data for these economies quite well provided the moments of some key shocks are changed vis-à-vis the typical specification chosen for already developed economies. ${ }^{2}$

To my knowledge, this paper provides the first taxonomy of the broad macroeconomic mechanisms - adjustment in (intertemporal) prices vs adjustment in quantities (output, investment government spending) - through which China's external adjustment can be expected to occur. It is not my aim to pin down a single mechanism that can explain China's high savings rate, which according to Yang, Zhang and Zhu (2010) has many causes and remains a 'puzzle'. However, I discuss at a more specific level how certain

\footnotetext{
${ }^{2}$ For example, Aguiar and Gopinath (2007) argue that a higher variance of trend shocks to total factor productivity can explain why net exports are more anticyclical in emerging than in developed markets. For a similar setup see also Neumeyer and Perri (2005). None of these papers denies the importance of frictions in explaining business cycles in emerging markets-quite to the contrary. But they argue that these frictions manifest themselves rather in changes in the structure of shocks, and not so much in the structure of the basic model. This insight allows the basic model to be used as a vehicle to collect and discuss stylized facts.
} 
mechanisms that have been proposed in the literature could plausibly map in to the broad channels of adjustment that I identify in my analysis.

To start, there are a number of possible interpretations of my finding that expected changes in the price of non-tradeable goods drive China's current account: the declining provision of public services (medical care, education) and housing in China and the ensuing rise in the price of these non-tradeable goods and services present a strong incentive for private households to save. This 'breaking-of-the-iron-rice-bowl' interpretation is in line with micro-data evidence as reported in e.g. Chamon and Prasad (2010) who identify exactly these factors as the drivers of the secular increase in the savings rate of Chinese private households during the 1980s and 1990s. ${ }^{3}$ China's changing demographics also likely plays an important role. As recently noted by Wei and Zhang (2009), a rising sex ratio provides a strong competitive savings incentive, especially for parents with a son, since wealth accumulation may help increase a son's chances in the marriage market. This excess saving could spill over into prices for housing and education.

A second robust fact that I document is the quite remarkable showing of intertemporal variation in national cash flow - output less investment and government spending - as a factor driving current account dynamics. In fact, China's current account predicts declines of national cash flow relative to its long-term trend. ${ }^{4}$ That would seem to be at odds with the increasing output growth rates of the recent past. However, as shown in Panel B in Figure 1 which presents the main data, China's investment has grown much faster than output over much of the last decade. One explanation of this pattern is that firms outside the state sector may have to finance future investment from retained earnings if they cannot access private capital markets (see e.g. Song, Storesletten and Zilibotti (2011)). As the

\footnotetext{
${ }^{3}$ The fixed exchange rate regime may have facilitated this transition: the ensuing accumulation of foreign reserves provides a centralized way to back up the public banking sector and to increase its credibility. This in turn puts private households - most of which do not otherwise have access to financial markets - in a position to hold international assets indirectly by channeling their savings through the public banking This interpretation is supported by the findings in Caballero, Farhi and Gourinchas (2008) who argue that official reserve accumulation is indirectly held by the private sector through low-return sterilization bonds.

${ }^{4}$ This finding has an interesting correspondence in the Engel and Rogers (2006) result that US output growth projections are consistent with the size of the US deficit.
} 
share of these firms in value added has increased, so may have the aggregate (corporate) savings rate. Increases in (firm) saving then predict subsequent increases in investment.

Encouraged by the empirical performance of the simple present-value model of the current account on Chinese data, in the second part of the paper I ask whether the model also holds conditional on a set of broadly specified structural shocks. The specific structure of my empirical model allows me to identify permanent and transitory shocks with only minimal theoretical restrictions. I then build on Kano (2008) and propose a novel way to distinguish between a country-specific and a global variety of both permanent and transitory shocks: country-specific shocks should not affect the world interest rate whereas global shocks do. From a theoretical point of view, these two categories of shocks should be crucially important for current account dynamics. ${ }^{5}$ My results suggest the following: first, the estimated response of China's current account is generally in line with the predicted response of the channels of external adjustment to both transitory and permanent shocks (be they global or country-specific). Secondly, I find that permanent global shocks are an important driver of China's current account. They are associated with a marked increase in the current account balance and a prolonged decline in the world real interest rate. This pattern is consistent with the predictions of recent theoretical models in which factors related to China's domestic financial development are driving the surplus and lead to declines in global interest rates. ${ }^{6}$

The paper is now structured as follows. Section two outlines the theoretical framework and explains the econometrics used to test it. Section three presents the data and section four the main results. Section five offers further discussion and concludes.

\footnotetext{
${ }^{5}$ For the importance of permanent vs. transitory shocks see Aguiar and Gopinath (2007) and Hoffmann (2001b). For country-specific vs. global shocks see Glick and Rogoff (1995), Hoffmann (2001b), Engel and Rogers (2006) and Kano (2008).

${ }^{6}$ See Caballero, Farhi and Gourinchas (2008) and Mendoza, Quadrini and Rios-Rull (2009).
} 


\section{The framework}

The empirical analysis in this paper is based on a simple intertemporal model of the current account in which the representative consumer maximizes

$$
\sum_{t=0}^{\infty} \beta^{t} E_{0}\left[\frac{X\left(C_{N t}, C_{T t}\right)^{1-\gamma}}{1-\gamma}\right]
$$

where $C_{N}$ is non-tradeables consumption, $C_{T}$ is tradeables consumption and $X($.$) defines$ a consumption bundle to be defined below. We denote the value of consumption in terms of tradeable goods with

$$
C_{t}=C_{T t}+P C_{N t}
$$

where $P$ is the relative price of the non-tradeable good. Then we write the budget constraint (expressed in tradeable goods) as

$$
B_{t}=\left(1+r_{t}^{T}\right) B_{t-1}+Y_{t}-I_{t}-G_{t}-C_{t}
$$

where $B_{t}$ is the stock of foreign assets and $Y_{t}, I_{t}, G_{t}$ and $C_{t}$ denote the value of real output, investment, government consumption and private consumption respectively. The term $r_{t}^{T}$ denotes the interest rate (expressed in terms of tradeable goods) that the country obtains on its holdings of foreign assets, $B$. In this model, the current account balance is given by

$$
C A_{t}=\Delta B_{t}=r_{t}^{T} B_{t-1}+N O_{t}-C_{t}
$$

where I introduce the notation $N O_{t}=Y_{t}-I_{t}-G_{t}$ to denote net output, i.e. the national cash flow available for consumption .

In a frictionless economy, $r_{t}^{T}$ equals the world interest rate. However, I follow Gourinchas and Jeanne (2009) and allow for a friction in the intertemporal allocation of con- 
sumption that drives a wedge between the home and the world interest rate $r_{t}^{W}$ so that

$$
1+r_{t}^{T}=\left(1+r_{t}^{W}\right)\left(1-\tau_{t}^{s}\right)
$$

where $\tau_{t}^{s}$ captures the 'savings wedge'. Gourinchas and Jeanne (2009) have argued very convincingly that such a 'savings wedge' - rather than frictions in the accumulation of capital - are important in explaining the capital allocation puzzle, i.e. the empirical fact that current accounts and GDP growth are positively correlated in a large cross-section of countries, particular among emerging economies. ${ }^{7}$ Note that $\tau_{t}^{s}$ can take both positive and negative values: a positive value would be friction that deters saving (amounting to a tax on foreign income) whereas negative values of $\tau_{s}$ would amount to an implicit subsidy of savings. For China, as a prime example of a high-growth / high savings economy, we would expect negative values of $\tau^{s}$ on average.

To complete the model setup, I assume (as e.g. Bergin and Sheffrin (2000) ) that the consumption bundle $X$ is a CES aggregate of tradeable and non-tradeable goods with unit elasticity of substitution, so that

$$
X_{t}=C_{T t}^{\alpha} \times C_{N t}^{1-\alpha}
$$

In this setting, it is well known that the intertemporal consumption allocation can be solved for independently from the intratemporal allocation between tradeable and nontradeable goods. Specifically, we can define the price index of aggregate consumption by recognizing that for any such index $P_{t}^{*}$ it must be true that $P_{t}^{*} X_{t}=C_{T t}+P C_{N t}=C_{t}$ for all $P_{t}$. Then replacing $C_{t}$ with $P_{t}^{*} X_{t}$ in the budget constraint, one obtains the Euler equation

$$
E_{t}\left(\beta \frac{P_{t}^{*}}{P_{t+1}^{*}}\left(\frac{X_{t}}{X_{t+1}}\right)^{\gamma}\left(1+r_{t+1}^{T}\right)\right)=1
$$

\footnotetext{
${ }^{7}$ Here, I derive the model solution under the assumption of a time-varying savings wedge. In my empirical implementation below, I followGourinchas and Jeanne (2009) and assume that $\tau^{s}$ is constant.
} 
which can be rewritten in terms of aggregate consumption expenditure as

$$
E_{t}\left(\beta\left(\frac{C_{t}}{C_{t+1}}\right)^{\gamma}\left(\frac{P_{t}^{*}}{P_{t+1}^{*}}\right)^{1-\gamma}\left(1+r_{t+1}^{T}\right)\right)=1
$$

As shown in Obstfeld and Rogoff (1995), the aggregate price index for consumption is an expenditure-weighted CES aggregate of the tradeable and non-tradeable goods prices so that $P_{t+1}^{*} / P_{t}^{*}=\left(P_{t+1} / P_{t}\right)^{1-\alpha}$. Hence, (2) links aggregate consumption expenditure growth to the consumption-based real interest rate, which is the world-real interest rate corrected for the savings wedge and real exchange rate changes (defined as the change in the relative price of non-traded goods). Assuming that consumption growth, the real exchange rate, and the real interest rate are jointly log-normal, Bergin and Sheffrin (2000) show that this condition can be log-linearized to obtain

$$
E_{t}\left(\Delta c_{t+1}\right)=\frac{1}{\gamma} E_{t}\left(r_{t+1}\right)+\text { constant }
$$

where $r_{t}$ is the consumption-based real interest rate

$$
r_{t+1}=r_{t+1}^{T}+(1-\alpha)(\gamma-1) \Delta p_{t+1}
$$

We are now interested in obtaining a representation for the current account. As is well known, this model does not have a closed-form solution, but Bergin and Sheffrin (2000) and Kano (2008) have suggested different log-linearizations of the intertemporal budget constraint. Here, I follow Kano and consider a log-linearization of the current account / net output ratio which can be represented as

$$
\frac{\widetilde{C A_{t}}}{N O_{t}}=b \widetilde{r}_{t}^{T}+c \sum_{k=1}^{\infty} \kappa^{k} E_{t}\left\{\Delta \widetilde{c}_{t+k}-\widetilde{r}_{t+k}^{T}\right\}+\sum_{k=1}^{\infty} \kappa^{k} E_{t}\left\{\widetilde{r}_{t+k}^{T}-\Delta \widetilde{n o}_{t+k}\right\}
$$

where $\Delta n o$ is the growth rate of net output and the tilde denotes deviations from the 
unconditional mean of the respective variable. The parameters $b, c$, are the long-term means of $B / N O, C / N O$ respectively and $\kappa=\exp \left[E\left(\Delta n o_{t}\right)-E\left(r_{t}^{T}\right)\right]$. Note that the above approximation follows directly from the intertemporal budget constraint. The condition is therefore consistent with arbitrary processes for investment and output. In particular it is worth emphasizing that this identity will also hold in a much richer model than the one I discuss here, e.g. in a production economy in which both output and investment are endogenous. ${ }^{8}$

I now substitute for consumption growth and the real interest rate term on the right hand side of the expression using the fact that $r_{t+1}=r_{t+1}^{T}+(1-\alpha)(\gamma-1) \Delta p_{t+1} .{ }^{9}$ Plugging in for $r_{t+1} / \gamma=E\left(\Delta c_{t+1}\right)$, and using the approximation $r_{t}^{T}=r_{t}^{W}-\tau_{t}^{s}$, I obtain the following expression for the current account

$\frac{\widetilde{C A_{t}}}{N O_{t}}=b \widetilde{r}_{t}^{W}+[1-\phi] \sum_{k=1}^{\infty} \kappa^{k} E_{t} \widetilde{r}_{t+k}+\phi \sum_{k=1}^{\infty} \kappa^{k} E_{t} \widetilde{\Delta q_{t+k}}-\sum_{k=1}^{\infty} \kappa^{k} E_{t} \Delta \widetilde{n o} t+k-\left[b \widetilde{\tau}_{t}^{s}+[1-\phi] \sum_{k=1}^{\infty} \kappa^{k} E_{t} \widetilde{\tau}_{t+k}^{s}\right]$

where I have introduced additional notation so that $\phi=c\left(1-\frac{1}{\gamma}\right)$ and $\Delta q_{t+1}=(1-\alpha) \Delta p_{t+1}$ is the real exchange rate.

This equation suggests five channels of current account adjustment. The first channel is the impact of interest rate variation on net factor income flows. The second term is consumption-tilting due to expected variation in the world real rate of interest: if interest rates are temporarily high, so that the sum of future interest-rate deviations from the longterm mean interest rate is positive, consumers will want to defer consumption and save more. I call this the global tilting term since it is determined by global variation in interest rates. Clearly, this global tilting effect becomes stronger as the intertemporal elasticity of substitution, $1 / \gamma$, increases. The third term is the effect on intertemporal substitution of

\footnotetext{
${ }^{8}$ Clearly, additional cross-equation restrictions will arise in a model with endogenous investment. For example, with adjustment costs there will be an additional present-value constraint reflecting Tobin's q. However, the present-value restriction for the current account will still hold, given the dynamics of output and investment. In my empirical approach, I prefer not to impose further cross-equation restrictions but let the data determine a statistical description of the time-series dynamics of net output.

${ }^{9}$ This follows Bergin and Sheffrin (2000) and Bouakez and Kano (2008). However, these models do not feature a savings wedge.
} 
expected real exchange rate changes. If the price of the domestic consumption bundle relative to tradeable goods is expected to rise in the future, there is an incentive to save more. I refer to this channel as 'domestic tilting' since it is driven by relative variation in expected prices of only domestically consumed (non-tradeable) to both internationally and domestically consumed (tradeable) goods. According to my results below, this channel is important in the data and is likely to capture the effect of expected price increases for housing, medical care and education on China's savings rate. ${ }^{10}$ The fourth term reflects the classical consumption smoothing channel: if output is below (above) trend, so that the sum of its expected changes is positive (negative), the country should run a deficit (surplus) ceteris paribus.

Finally, the fifth term reflects the impact of expected variation in financial frictions - the savings wedge - on the current account. The impact is completely symmetric to variation in the world interest rate. If $0<\phi<1$, a temporary drop of $\tau_{t}^{s}$ below its long-run mean will turn the sum of expected future mean deviations $\widetilde{\tau}_{t+k}^{s}$ negative, thus increasing the current account ceteris paribus: it will be optimal to take advantage of the temporary subsidy to savings and to defer consumption for a while. Conversely, a temporary increase in $\tau_{t}^{s}$ will tend to lower the current account.

If the savings wedge $\tau_{t}^{s}=\tau^{s}$ is constant, then $\frac{\widetilde{C A_{t}}}{N O_{t}}$ becomes

\footnotetext{
${ }^{10}$ As a possible extension of the model one may want to consider the case in which the non-tradeable good is durable, reflecting e.g. the stock of housing (see Iscan (2002) for an early example of a present-value model of the current account with non-tradeables and durables). In such a model, an expected rise in the price of non-tradeable goods may induce households to borrow (in terms of tradeables) and to purchase houses today. This would lead to a current account deficit ceteris paribus. Aizenman and Jinjarak (2009) provide evidence that current account deficits are correlated with subsequent house price increases in developed markets and Gete (2010) develops a theoretical model that matches this empirical fact. While housing is an important element of non-tradeable expenditure, I would expect that the prices of largely non-tradeable (and non-durable) services such as medical care and education are also important for savings decisions in a country such as China. I therefore do not wish to constrain the dynamics of non-tradeable consumption any further and leave it for future research to fully explore the implications of introducing a durable good into the framework here. However, it should be noted that my model can accommodate the effect described by Aizenman and Jinjarak (2009) in a reduced-form way: In my empirical implementation I allow for the possibility that the intertemporal elasticity of substitution is bigger than one. This would allow expected price increases in non-tradeables to turn the current account into deficit. My empirical results below strongly suggest that the intertemporal elasticity of substitution is below unity, though. This implies that expected price increases for non-tradeables lead to surpluses in the current account.
} 


$$
\frac{\widetilde{C A_{t}}}{N O_{t}}=\overrightarrow{b r_{t}^{W}}+\left[1-c\left(1-\frac{1}{\gamma}\right)\right] \sum_{k=1}^{\infty} \kappa^{k} E_{t} \widetilde{r}_{t+k}+c\left[1-\frac{1}{\gamma}\right] \sum_{k=1}^{\infty} \kappa^{k} E_{t} \widetilde{\Delta q_{t+k}}-\sum_{k=1}^{\infty} \kappa^{k} E_{t} \Delta \widetilde{n O_{t+k}}
$$

This is the equation that would hold in a frictionless model, i.e. if $\tau^{s}=0 .{ }^{11}$ But it is important to emphasize here that it holds even if the mean savings wedge $\tau^{s} \neq 0$, i.e. in the presence of a time-invariant savings friction. ${ }^{12}$ Clearly, whether or not $\tau_{t}^{s}$ varies over time and whether it has a constant mean is an empirical question. My way of answering this question is to test equation (5) and to ask how far it is from the data. Therefore equation (5) is the focus of my empirical analysis in the remainder of the paper. ${ }^{13}$

To test equation (5), I proxy the expectation terms on the right hand side of (4) using a vector autoregressive model (VAR):

$$
X_{t}=\sum_{l=1}^{p} \boldsymbol{A} X_{t-l}+\varepsilon_{t}
$$

where $X_{t}=\left[\begin{array}{llll}\Delta n o_{t} & \Delta q_{t} & r_{t}^{W} & C A_{t} / N O_{t}\end{array}\right]^{\prime}$ is the vector of endogenous variables, the $\boldsymbol{A}_{l}$ are $4 \times 4$ coefficient matrices of the $p$-th order VAR and $\varepsilon_{t}$ is the vector of reduced-form residuals. Stacking $Z_{t}=\left[\begin{array}{llll}X_{t}, & X_{t-1}, & \ldots & , X_{t-p+1}\end{array}\right]^{\prime}$, write the VAR companion form as $\operatorname{VAR}(1)$ so that

$$
Z_{t}=\boldsymbol{A} Z_{t-1}+U_{t}
$$

where $\boldsymbol{A}$ is the companion matrix and $U_{t}=\left[\begin{array}{llll}\varepsilon_{t}, & 0, & \ldots\end{array}\right]$ the vector of shocks. Then, once the VAR-parameters has been estimated, the expectation terms are easily backed out

\footnotetext{
${ }^{11}$ Equation 5 is a special case of equation (18) studied in Bouakez and Kano (2008). Their model also allows for changes in the terms of trade and nests the model here if $\tau_{t}^{s}=0$.

${ }^{12}$ While the assumption that $\tau^{s} \neq 0$ does not affect the formal derivation of equation (5), it does affect the dynamics of the current account through its impact on the 'discount factor' $\kappa=$ $\exp \left[E\left(\Delta n o_{t}\right)-E\left(r_{t}^{w}\right)+E\left(\tau_{t}^{s}\right)\right]$. Clearly, with a savings subsidy $\left(\tau_{s}=E\left(\tau_{t}^{s}\right)<0\right)$ we will have a lower value of $\kappa$ than in a frictionless model. Assuming that $\tau^{s} \neq 0$ also affects the mean of the the current account itself. I return to these points in my calibration of the model parameters below.

${ }^{13}$ This approach is similar to Ghosh (1995) who uses a frictionless model to back out an implied current account and compares the volatility of the predicted and the actual current accounts. Based on G7-data, he finds the data excessively volatile, concluding that there is too much capital mobility.
} 
as

$$
\sum_{k=1}^{\infty} \kappa^{k} \boldsymbol{E}_{t} x_{t+k}=\boldsymbol{e}_{x}^{\prime} \kappa \boldsymbol{A}[\boldsymbol{I}-\kappa \boldsymbol{A}]^{-1} Z_{t}
$$

where $x_{t}$ stands, in turn, for $\Delta n o_{t}, \Delta q_{t}, r_{t}^{W}, \frac{C A_{t}}{N O_{t}}$ and $\boldsymbol{e}_{x}$ is the unit vector associated with the position of $x$ in the vector $Z_{t}$ (i.e. the first unit vector for $\Delta n o$, the second for $\Delta q_{t}$ etc.). Plugging this representation of the expectation terms into (4) above, one gets the $C A / N O$ ratio predicted by the model

$$
\frac{\widehat{C A}_{t}}{N O_{t}}=b \widetilde{r}_{t}^{W}+\left[(1-\phi) e_{r}^{\prime}+\phi e_{\Delta q}^{\prime}-e_{\Delta n o}^{\prime}\right] \kappa \boldsymbol{A}[\boldsymbol{I}-\kappa \boldsymbol{A}]^{-1} Z_{t}
$$

where again $\phi=\left(1-\frac{1}{\gamma}\right) c$ and where I denote the predicted value from the model with a hat.

For any known set of parameter values $b, 1 / \gamma$, and $c$ the predicted current account can now be compared to the actual current account. This can be done either through an informal comparison of the predicted current account with the data (in terms of correlation and variance) or formally, based on a Wald test. ${ }^{14}$ I report all of these statistics below. The steady-state share of foreign assets, $b$, and $c$ (the long-term consumption / net output ratio) could in principle be calibrated from the data, while the elasticity of intertemporal substitution, $1 / \gamma$, is unobservable. Here, I only fix $c$ from the data and estimate both $1 / \gamma$ and $b$ using a GMM-procedure in which I perform a grid search to minimize the in-sample sum of squared deviations between the actual and predicted $C A / N O$. The reason for not imputing $b$ from the data directly is is that the long-term net foreign asset position may actually be very imperfectly proxied through reported net foreign asset positions or through cumulated current accounts (see Lane and Milesi-Ferretti (2007)). This is particularly true for China, for which some authors have argued that current account data may understate

\footnotetext{
${ }^{14}$ Rewriting equation (7) as $\boldsymbol{e}_{c a}^{\prime}=b \boldsymbol{e}_{r}^{\prime}+\left[(1-\phi) \boldsymbol{e}_{r}^{\prime}+\phi \boldsymbol{e}_{\Delta q}^{\prime}-\boldsymbol{e}_{\Delta n o}^{\prime}\right] \kappa \boldsymbol{A}[I-\kappa \boldsymbol{A}]^{-1}$ and denoting the right hand side of this restriction with $\boldsymbol{\Psi}(\boldsymbol{A})$, the Wald-statistics $\left[\boldsymbol{e}_{c a}^{\prime}-\boldsymbol{\Psi}(\boldsymbol{A})\right] \frac{\partial \boldsymbol{\Psi}(\boldsymbol{A})}{\partial \boldsymbol{A}} \operatorname{var}(\boldsymbol{A})^{-1} \frac{\partial \boldsymbol{\Psi}(A)^{\prime}}{\partial A}\left[\boldsymbol{e}_{c a}^{\prime}-\boldsymbol{\Psi}(\boldsymbol{A})\right]^{\prime}$ is asymptotically distributed as a $\chi^{2}$ with $m$ degrees of freedom where $m$ is the dimension of the companion matrix $\boldsymbol{A}$.
} 
actual foreign liabilities and overstate foreign assets (see Zhang (2008)).

Based on the representation (7), I now decompose the variance of the current account as follows. Write the component that is unexplained by the model as res $=C A / N O-$ $C \widehat{A / N} O$, take the variance on both sides and plug in for $C \widehat{A / N} O$ from (7). Then, dividing by $\operatorname{var}(C A / N O)$, one gets

$$
1=\beta_{b}+\beta_{r}+\beta_{\Delta q}+\beta_{\Delta n o}+\beta_{r e s}
$$

where

$$
\begin{aligned}
\beta_{b} & =\frac{\operatorname{cov}\left(b\left(\boldsymbol{e}_{r}^{\prime} Z_{t}, C A / N O\right)\right.}{\operatorname{var}(C A / N O)} \\
\beta_{r} & =\frac{\operatorname{cov}\left((1-\phi) \boldsymbol{e}_{r}^{\prime} \kappa \boldsymbol{A}[\boldsymbol{I}-\kappa \boldsymbol{A}]^{-1} Z_{t}, C A / N O\right)}{\operatorname{var}(C A / N O)} \\
\beta_{\Delta q} & =\frac{\operatorname{cov}\left(\phi \boldsymbol{e}_{\Delta q}^{\prime} \kappa \boldsymbol{A}[\boldsymbol{I}-\kappa \boldsymbol{A}]^{-1} Z_{t}, C A / N O\right)}{\operatorname{var}(C A / N O)} \\
\beta_{\Delta n o} & =\frac{\operatorname{cov}\left(-\boldsymbol{e}_{\Delta n o}^{\prime} \kappa \boldsymbol{A}[\boldsymbol{I}-\kappa \boldsymbol{A}]^{-1} Z_{t}, C A / N O\right)}{\operatorname{var}(C A / N O)} \\
\beta_{\text {res }} & =\frac{\operatorname{cov}(r e s, C A / N O)}{\operatorname{var}(C A / N O)}
\end{aligned}
$$

where again $\phi=\left(1-\frac{1}{\gamma}\right) c$. Here, $\beta_{b}$ is the contribution of net factor income to the variance of the current account, $\beta_{r}$ the contribution of (expected) variation in the world real rate of interest (the global tilting factor), $\beta_{\Delta q}$ the contribution of expected changes in the real exchange rate (the domestic tilting factor), and $\beta_{\Delta n o}$ the contribution of output variation (consumption smoothing). The coefficient $\beta_{\text {res }}$ is the fraction of the variance of the current account that remains unexplained by the model.

This decomposition is similar in spirit to the one suggested by Gourinchas and Rey 
(2007), but it is more tightly constrained by economic theory: equation (4) is derived under the assumption of intertemporal optimality in consumption (i.e. that the Eulerequation (2) holds). The decomposition here therefore also allows to identify the role of global and domestic tilting factors in external adjustment. ${ }^{15}$

I now use this framework to identify the drivers of China's current account adjustment. The next section first describes the data set. Section four presents empirical results.

\section{Data and Estimation}

The main data used in this study are from the International Monetary Fund's International Financial Statistics and were taken from the June 2009 CD. The data are annual and range from 1982 to 2007. China's economic reform started in 1979 but transformation to a a market economy was gradual in the beginning. I therefore report most results based on a somewhat shorter baseline sample starting in 1987.

Investment is constructed as the sum of gross fixed capital formation (line xxx93E) and inventory investment (line xxx93I). GDP is taken from line xxx99B, government consumption expenditure is from line xxx91F. Net output, GDP less investment and government consumption, is then turned into real quantities by deflating with the GDP deflator (92499BIPZF...). Further, I turn this variable into per capita terms using the population data from the IFS.

I use two measures of the current account balance. The baseline measure is the official series from the IFS (series code 92478ALDZF... ). The second measure is obtained from

\footnotetext{
${ }^{15}$ The setup here abstracts from the role of valuation effects on the stock of foreign assets. For China this is justifiable on a number of grounds: first, using quarterly data for the U.S., Gourinchas and Rey (2007) find these effects to matter mainly at short to medium horizons. The focus here is on medium- to longer term patterns of external adjustment. Specifically, since quarterly data for China do not exist over long time periods, my data here is necessarily annual. In addition, reliable data for non-reserve foreign assets seem hard to obtain. Finally, we may expect valuation effects to play a limited role simply because most of China's recent foreign assets accumulation is held in the form of foreign reserves which have been used to stabilize the nominal exchange rate.
} 
Zhang (2008). This series is identical to the IFS until 2003 but makes some important adjustments for the last years of the sample. Specifically, Zhang (2008) argues that current account surpluses since 2003 are considerably overstated in official statistics. He identifies two main sources of measurement error: first, a large part of China's foreign trade is actually accounted for by foreign firms. According to the IMF's Balance of Payments (BoP) manual, returns on foreign direct investment should figure in a country's current account as a negative item, irrespective of whether these returns are repatriated or not. For China, the rate of return on foreign firms investment are likely to be under-reported. Based on BoP data, they amount to around 5 percent in 2007, whereas a number of studies that estimate the return on capital directly reach estimates of an average rate of return of 14 percent. This discrepancy could lead to a considerably overstatement of China's current account surplus.

A second channel identified by Zhang (2008) is the incentive for mis-invoicing of imports and exports by foreign firms which could be presented by China's fixed exchange rate in conjunction with its capital control regime. Revaluation expectations for the Renminbi (RMB) will provide an incentive for capital inflows which, however, are officially restricted. One way for foreign firms to circumvent these capital controls is to under-invoice purchases from the foreign mother companies and to over-invoice their exports which would lead to an upward bias in the current account balance. Zhang provides empirical evidence for the quantitative importance of this channel. I therefore report many of my results based on Zhang's adjusted data and refer to these data as the valuation-adjusted current account. Doing so serves as a robustness check as to how strongly the results obtained from official data are affected by measurement error and, in particular, revaluation expectations.

I also employ two measures of the relative price of non-tradeable goods. The first is again taken from the IFS, the real effective exchange rate based on consumer prices (series code 924..RECZF... ). As a more direct measure of the relative price of non-tradeable goods, I use a breakdown of the CPI into various expenditure categories (food, tobacco, 
clothing, household facilities, medical care, traffic and communications, recreation and residence) and construct the non-tradeable component as the ratio of the CPI for housing, medical care and residence relative to the aggregate CPI. These data are, however, only available from 1994 onwards. ${ }^{16}$ Finally, I use the annual average of the 3-months US Tbill rate less CPI inflation to proxy for the real world interest rate. For reference in the discussion of my results below, Figure 1 plots the main data used in the analysis.

The VAR in the four variables $X_{t}=\left[\begin{array}{llll}\Delta n o_{t} & \Delta q_{t} & r_{t}^{W} & C A_{t} / N O_{t}\end{array}\right]^{\prime}$ is estimated with two lags. To obtain the estimates of $b$ and $1 / \gamma$, I use the GMM- procedure outlined above: based on a grid search, I choose the values of $b$ and $1 / \gamma$ so as to minimize the sum of squared deviations $\sum_{t=1}^{T}\left(C \widehat{A_{t} / N} O_{t}-C A_{t} / N O_{t}\right)^{2}$. In so doing, I fix $c$ to the long-run mean of the consumption-net output ratio (0.97) and choose the discount factor $\kappa=0.93 .{ }^{17}$ To initialize the grid search, I obtain averages for China's net foreign asset position (which is also available from the IFS but only for the last couple of years). I then let the grid search procedure choose $b$ in the interval of plus / minus one hundred percent of net output around this initial value. The grid search for $1 / \gamma$ is constrained to the positive unit interval, which is the range that is typically considered as plausible in the macroeconomic literature. Allowing values greater than one for $1 / \gamma$ in the grid search does not change the estimates, though. The results reported below are also robust to fixing $1 / \gamma$ (instead of estimating it) to a range of values in the unit interval.

\footnotetext{
${ }^{16}$ I thank the Hong Kong Monetary Authority for kindly providing these data.

${ }^{17}$ Alternative choices of $c$ and $\kappa$ between 0.9 and 1.00 have no major effects on the results. Nevertheless it is interesting to note that $\kappa=\kappa_{F L} \exp \left(\tau^{s}\right)$ where $\kappa_{F L}$ is the parameter in the frictionless model as it might be applied to a developed country. Then assuming that $\kappa=0.93$ is consistent with $\kappa_{F L}=0.98$ and a savings wedge of $\tau_{s}=-0.05$. Gourinchas and Jeanne (2009) estimate $\tau^{S}=-0.04$ for China for the period 1982-2000.
} 


\section{Results}

Figure 2A, Panel I plots the predicted against the actual current account for the baseline period 1987-2007. Panel II plots the same figure for the full sample, 1982-2007. In both cases, the correlation between the actual and the predicted time series appears visually very high across the whole sample period. The actual and the predicted current account also match in terms of relative variability. However, while the specification estimated from the shorter period explains a considerable part of the increase in the current account surplus since the beginning of the 2000s, the model estimated from the full sample seems to do less well on that account. The first two columns of Table 1 report more formal evidence, first on correlations and relative variability, second on the estimated parameter values. The table also shows the Wald tests statistics of the cross-equation restrictions (7). While the cross-equation restrictions are rejected on the full sample, they clearly cannot be rejected on the baseline sample. In both samples correlations exceed 0.8 and the relative volatilities of the actual and the predicted current account are close to unity. ${ }^{18}$ The structural parameters are also similar across the two samples. For both the estimate of the intertemporal elasticity of substitution $(1 / \gamma)$ is well below unity. The estimate of the long-run mean of the share of foreign assets, $b$, is virtually zero in both cases.

The lower two panels of Figure 2A plot the actual against the estimated current account that I obtain based on Zhang's (2008) valuation-adjusted current account data. Measures of fit and estimated parameter values are in the third and fourth columns of Table 1. Again, the correlation is visually striking. Interestingly, the model now mimics virtually all of the pick-up in the Chinese surplus after 2001, irrespective of whether the full or the baseline sample are used. When the model is estimated on the long sample, it seems that the overall fit is comparable to the model estimated on official data for the same period overall, but at least visually - the model based on valuation adjusted data seems to perform better on

\footnotetext{
${ }^{18}$ In particular, getting relative volatilities to be of the same order of magnitude often proves difficult in empirical implementations of present-value models (see e.g. Kano (2008), Campbell and Shiller (1987)).
} 
the last couple of years (i.e. exactly those years for which current account data are subject to the adjustment). As was the case for the model based on official post-2003 data, the Wald test rejects on the long sample but does not reject on the shorter baseline sample. The estimate of the intertemporal elasticity of substitution changes very little vis-à-vis the specification based on official data nor does the long-run share of foreign assets which is still estimated to be close to zero. ${ }^{19}$

The data used so far in this paper ends in 2007. At the time this research was begun, this was the most recently available. Also, Zhang's valuation adjusted data are to date available only till 2007. In order to keep the results obtained from the the IFS and the valuation-adjusted data sets comparable, results in the paper therefore generally cover the period from 1982 or 1987 to 2007.

However, for robustness, in Figure 2B and in the last column of Table 1, I also report some key results based on an updated version of the IFS-data set (from the May 2012 CD) that runs from 1982 till 2010. Besides three additional annual observations for 20082010, this updated data set also contains certain subsequent data revisions and therefore, even on pre-2007 data, is not identical to the IFS-data set (June 2009 vintage) for 19822007 used above and in the remainder of the paper. It is therefore interesting to see how the model does on this updated data set. As is apparent from Figure 2B, it also fits the updated data very well. Specifically, the model also does well in replicating the peak in the current account in 2007 and its subsequent decline. The impression of an overall quite considerable fit is confirmed by the formal statistics reported in the last column of Table 1. The Wald test cannot reject the model at the conventional significance levels.

\footnotetext{
${ }^{19}$ That the estimate of $b$ is so close to zero seems at odds with the almost explosive path of China's net foreign asset position over the last years. Two remarks are in order: first, the number reported here is an estimated (in-sample) long-run average value. Very little information about China's foreign asset position exists for most of the sample period considered here. As a matter of fact, however, it is likely that China's net foreign asset position has only turned positive shortly after the turn of the millennium (see Dollar and Kraay (2006)). This may makes a sample average close to zero appear quite plausible. Secondly, some theoretical papers have attempted to calibrate the long-run value of China's external position, projecting current demographic and financial development patterns into the future. For example, Dollar and Kraay (2006) find a slightly negative long-term average asset position, again reasonably close to the numbers estimated here.
} 
Reassuringly, the parameter estimates are very similar to those obtained from both the valuation-adjusted data and the June 2009 vintage of IFS data which both run till 2007. In the remainder of the paper, I therefore report results mainly for these two data sets ending in 2007. ${ }^{20}$

Figure 3 provides a graphical representation of the individual expectation components in the predicted current account. Panel A is based on the IFS data set and it is apparent that the real exchange rate channel plays a key role. Turning to the formal variance decomposition (8), this impression is confirmed: as shown in the first column of Table 2 , the exchange rate channel accounts for virtually all of the variability of the current account over the sample period when the IFS current account data are used. The global tilting factor and consumption smoothing seem to offset each other: the real interest rate channel seems to be positively correlated with current account fluctuations over the sample period, expected net output fluctuations appear negatively correlated with the overall effect netting out. The net factor income channel is virtually mute.

Turning to the longer sample period (2nd column of Table 2), the model still explains 70 percent of the variability in the actual current account, with the real exchange rate channel still accounting for virtually all of this. Expected net output changes do not seem to explain much nor do, again, net factor income flows. Expected variation in world interest rates is significantly negatively correlated with the current account, in contrast with the results for the shorter sample period. This fact seems to be at odds with the model, since the predicted current account from (4) should be positively correlated with the world real rate of interest-provided that $1-\phi=1-c\left(1-\frac{1}{\gamma}\right)$ is positive, which it is for the value of the intertemporal elasticity of substitution that we have estimated here. I explore this result in somewhat more detail below.

The third column provides the beta-decomposition for the period after 2001 (but with the expectations calculated from the VAR estimated from the long sample 1982-2007).

\footnotetext{
${ }^{20}$ Consequently, I continue to refer to the data from the June 2009 IFS-CD as the 'IFS data set' and to the period 1982-2007 as the 'full sample' and to the period 1987-2007 as the 'baseline sample'.
} 
This shows that the model estimated on the long sample cannot explain the IFS current account data after 2001: the share of the variance explained by the model drops to around 30 percent (i.e. $\beta_{u}$ rises to 0.68 ) for this subperiod.

As argued before, China's surplus in recent years may be subject to considerable measurement error due to revaluation expectations in the fixed exchange rate regime. The results so far may therefore tend to overstate the role of expected real exchange rate variation for external adjustment. I therefore provide results based on the Zhang (2008) valuationadjusted current account in Figure 3B and the last three columns of Table 2. Based on the shorter period, the model still explains almost 80 percent of the variance of $C A / N O$. Based on the long sample it still explains roundabout 70 percent, practically unchanged vis-à-vis the model estimated from official data. However, based on the valuation-adjusted data, the model now also does well on the post-2001 period: the share of the explained variance in CA remains stable at around 70 percent, in line with the estimate for the whole period 1982-2007.

Digging deeper into the relative contribution of the various channels, it is also apparent from Table 2 that the role of the exchange rate expectations channel is more subdued when the valuation-adjusted instead of the IFS current account data are used. For the post- 2001 period, price expectations now do not seem to play a role in this specification, a pattern that is also apparent from the graphs in Figure 2B. This is consistent with Zhang's interpretation that the difference between the valuation adjusted and the baseline current account represents mis-invoicing that is in turn driven by appreciation expectations. While, taken over the whole sample, expected changes in the real exchange rate are an important driver of current account fluctuations, the result here also suggests that expected variation in real exchange rates alone can only partially account for the run-up in China's surplus after the turn of the millennium.

Based on the valuation-adjusted current account, Figure 3B and the decomposition in Table 2 document a strong effect of the consumption smoothing channel (i.e. variation 
in expected net output growth) on current account dynamics. This is interesting because the consumption smoothing channel is center stage in even the most simplified version of the intertemporal model that do not allow for time variation in interest rates. It is the insights from this baseline textbook model (see Obstfeld and Rogoff (1996), ch. 2) that make surpluses in emerging markets - and in China in particular - appear puzzling in the first place: in an economy that is expected to grow fast over a protracted period of time we would expect to see persistent current account deficits. It is therefore surprising that this channel contributes so much to the explanation of China's recent surplus: the channel is significant over the whole sample and it contributes even more strongly after 2001, the period of rising surpluses. In looking for a possible explanation of this finding, it is important to note that the model does not make a claim about future GDP growth. Rather, what figures on the right hand side of the current-account equation (4) is national cash flow actually available for consumption, i.e. output less investment and government spending. A shock that leads to a persistent increase in output growth could lead the sum of growth rates in investment and government spending (weighted by their weights in aggregate GDP) to temporarily exceed that of output. This, in turn, could mean that long-term expected growth rates in net output turns negative, which would justify a current account surplus.It is apparent from the data plot in Figure 1 that this indeed what happened: in the first years of the new millennium investment grows much stronger than output.

Figure 4A illustrates the role that expected net out variation has played for the runup in China's current account during 2001-2007. The figure plots demeaned net output growth rates at different horizons (1, 2,3 and 5 years) against the long-term net output growth forecast from the VAR. The long-term net output growth forecast is the term $-\sum_{k=1}^{\infty} \kappa^{k} E_{t} \Delta \widetilde{n o}_{t+k}$ on the right hand side of (4) and reflects the consumption-smoothing component of the current account. If an expected decline in net output has played an important role in explaining the run-up of current account surpluses, then (absent large unexpected shocks to output) the ex-post correlation between actual long-term net output 
growth rates and those predicted from the VAR should be quite high. This is the case: first, note that the correlation between forecast and actual realization increases with the differencing horizon, reaching 0.58 at the 5-year horizon. Hence, the medium-term expected changes in net output that are implied by the VAR were eventually ratified by the subsequent realizations of net output growth. Second, it is important to note that medium- to long-term net output growth rates tend to fall below their long-run mean (i.e. turn negative in the graphs) soon after the turn of the millennium and the VAR forecasts reflect this pattern. Hence, the build-up of large current account surpluses after the turn of the millenium is consistent with the view that economic agents expected net output to decline, reflecting expected growth rates in investment and government spending that considerably outpaced those of gross domestic product. ${ }^{21}$

Figure 4B provides similar plots for real exchange rate changes, again at the $1,2,3$, and 5-year horizons. Again, this is meant to illustrate that the expected real exchange rate changes implied by the VAR (and that we have identified as another important source of variation of the current account) were to a large extent justified by the actual subsequent changes in that variable: as we would expect, the correlation between the long-run VAR forecast and actual changes increases with the forecast horizon. The magnitude of the VAR forecast also lines up nicely with actual exchange rate changes between one and two years ahead. At 3- and 5 years, the VAR forecast would seem too volatile relative to the data. This may not be surprising, though, given the difficulties of predicting exchange rates at long-horizons in general and given the repeated changes in the renminbi's exchange rate regime over the sample period (in 1994 and 2005) in particular. Still, the long-term VAR predictions contain significant information about the direction of exchange rate changes.

\footnotetext{
${ }^{21}$ These results mirror Engel and Rogers (2006) who show that projected US output growth rates are consistent with the US deficit. However, I stress that this pattern could itself be the result of the presence of financial frictions: given GDP growth, it implies that today's savings predict future increases in investment, which should not happen in a frictionless economy. One possible interpretation is that this reflects corporate savings of the many, quickly expanding small firms that do not have access to bank credit and that have to finance future investment from today's earnings (see e.g. Song, Storesletten and Zilibotti (2011) for a model in which financing frictions for small firms lead to high investment-savings correlations and for empirical evidence on this mechanism).
} 
The correlation between the long-term VAR forecast and the data at the 5-year horizon is 0.72 .

To explore the important role of the real exchange rate in external adjustment further, I repeat the exercise reported in Tables 1 and 2 but now based on an alternative measure of non-tradeables prices. I construct an index of the relative price of non-tradeables goods using a weighted average of the CPI for medical care and housing. This data is available monthly from 1994 onwards. To obtain an annual series, I take the end-of-year observations as stand-ins. Since estimating the model for the period after 1994 would make the sample very short, I splice this series together with the real exchange rate index used so far and report estimates for the period 1987-2007. The actual cumulated weight of housing and medical care in the CPI is around 0.25. But I assume it is not known a priori and extend the grid search procedure described above to also iterate over $\alpha$, the share of tradeables in the CPI. The results are in Table 3 and show that the flavor of all previous results is preserved also under this specification: the model still fits the current account data in terms of correlations and relative variability and the cross-equation restrictions are not rejected by the Wald test. The estimate of the elasticity of intertemporal substitution is 0.31 , the share of foreign assets is still estimated to be virtually zero. The share of non-tradeable goods, $(1-\alpha)=0.1$, is estimated to be somewhat lower than the actual weight in the data (0.25). The decomposition into the channels of external adjustment reveals a picture that is largely unchanged vis-à-vis the specifications in Table 2. Note that the results presented in Table 3 are based on the valuation-adjusted current account, which-as we have seen in Table 2- tends to lead to relatively low estimates of the contribution of real exchange rate changes to external adjustment. ${ }^{22}$ Still, roundabout 30 percent of the variation of the current account remain explained through adjustment in relative prices over the whole sample period and the model remains stable after 2001. This, once again, suggests that expected increases in the price of non-tradeables (rather than, say, expectations of nominal

\footnotetext{
${ }^{22}$ Indeed, using the official current account statistics would also lead to similar results to those in Table 2. These are not reported.
} 
exchange rate appreciation alone) are a very important driver of China's current account. However, they also suggest that the 'conventional' channel of intertemporal variation in national cash flow (net output) still has an important role to play: Figure 4B and the results in Table 3 show that expected price changes alone are not able to explain the increase in the surplus during the early 2000s if valuation-adjusted data is used.

\section{Out-of sample Stability and Robustness.}

The results presented here suggest that the model does quite well in explaining China's current account and in particular the surpluses after 2001. This raises the question whether the model overfits the data and in particular the trend in the current account after 2001. To address concerns about overfitting and parameter stability, I re-estimate the model on data from 1982 to 2001. Then, using the VAR coefficients and structural parameters from the pre-2001 period, I generate predicted values for the current account for the entire sample period according to equation (7), using observations on net output, real exchange rate changes and real interest rates from before 2001 and from 2002-2007. ${ }^{23}$ In very much the same way, I use equation (7) to 'backcast' pre-1987 current accounts from the model estimated from 1987-2007.

Figure 5A plots these out-of-sample back- and forecasts along with the actual current account (valuation adjusted). The figure shows that the model replicates current account over the entire sub-sample quite well, even if the fitted current account data are generated from parametrizations estimated from the two sub-samples 1982-2001 and 1987-2007. This seems true in particular for the run-up in current account surpluses after 2001.

Table 4 shows that the channels of external adjustment are also quite stable. Here, I run the decomposition (8) first for 1982-2001 and then based on the current accounts predicted for 1982-2007 from the VAR and structural parameter estimates obtained from the two sub-samples. Again the results are stable vis-à-vis earlier specifications. In partic-

\footnotetext{
${ }^{23}$ The model parameters for 1982-2001 are very similar to the estimates obtained in Table 1.
} 
ular, the patterns of adjustment are again very similar to the ones obtained for the period 1987-2001.

Note finally that the Wald-test of the cross-equation restrictions does not allow to reject the model at conventional significance levels when estimated on the period 1982-2001: the p-value of the Wald test is 0.55 Hence, while the cross-equation restrictions were rejected on the whole sample, they are not on the two sub-samples of almost equal length (19822001 and 1987-2001).

China's surpluses have substantially decreased since 2008 and it is therefore interesting to see if the model is able to replicate this decline out-of-sample, based on the estimates from the baseline sample, 1987-2007. Figure 5B shows that it is: the model (based on the parametrizations for 1987-2007 but using the updated IFS data (from the May 2012-CD) correctly replicates the timing and the magnitude of the peak in surpluses during 2008 and also does well on the quantitative extent of the subsequent decline. This further highlights the stability of the results and shows that the results reported in the paper are not driven by an in-sample overfitting of the model.

I summarize my findings in this section as follows: ultimately, it is impossible to rule out some structural instability over the sample period. This will not be surprising since structural change along many dimensions almost certainly will have affected Chinese data. But the results here clearly suggest that the effect of such instability on my model are likely to be limited: neither the inclusion of the early part of the sample (in which China's economy was only gradually opening up to market reform) nor the period of rapid growth and huge surpluses following 2001 seems to overturn the overall picture. ${ }^{24}$

\footnotetext{
${ }^{24} \mathrm{~A}$ final check to make sure that the model in this paper is not capturing something particular about Chinese data is to apply it to other economies with similar growth experiences. Furrer (2011) extends the analysis in this paper to several economies in South-East Asia. He reports that the model works well for South Korea Malaysia, Singapore and the Philippines.
} 


\subsection{Dynamic analysis}

From the results reported so far, it seems that two channels of external adjustment can explain the bulk of the variation in the Chinese current account: i) variation in expected national cash flows and ii) consumption tilting driven by expected increases in the relative price of non-tradeable goods. In this section, I examine whether the model response to a broad set of structural shocks is equally consistent with theoretical predictions and which of these shocks are responsible for this pattern.

The main methodical innovation I propose is a novel way to identify two groups of structural shocks: permanent and transitory and country-specific and global. While this fundamental distinction is of considerable importance in the theoretical and empirical literature, ${ }^{25}$ it is clearly also of independent interest to know to what extent $a$ ) fluctuations in China's current account are driven by trend and cyclical factors and $b$ ) to which extent they interact with global developments. My approach directly builds on previous work by myself (Hoffmann (2003, 2001b)) and by Kano (2008). While Hoffmann (2003, 2001b) uses the cointegrated structure of the present-value model of the current account to identify permanent and transitory shocks, his is a bivariate setup in quantity variabes only: output (or investment) and the current account. Country-specific and global shocks in this setup are disentangled using the restriction that the average country's current account cannot react to global shocks (see also Glick and Rogoff (1995)). Kano's model (Kano (2008)) also features intertemporal and intra-temporal prices (real exchange rates and real interest rates) but does not exploit the cointegrated structure of the PVMCA. In his setup, country-specific shocks are disentangled from global ones using the restriction that the real interest rate does not react to global shocks. While he can distinguish between a permanent and transitory country-specific shocks using Blanchard and Quah (1989) type

\footnotetext{
${ }^{25}$ On the importance of these two categories of shocks (permanent vs transitory and country-specific vs. global) see e.g. Glick and Rogoff (1995), Hoffmann (2003, 2001b), Aguiar and Gopinath (2007) Conversely,and Kano (2008). Nason and Rogers (2002a) examine various identification schemes inspired by the theory in an SVAR-context.
} 
long-run restrictions, his tri-variate VAR has only a single global shock. My four-variable setup here allows me to disentangle global and country-specific shocks of both the permanent and the transitory kind. It does so by coupling Kano's restriction for country-specific and global shocks with minimal identifying restrictions for permanent and transitory ones, exploiting the fact that the simple intertemporal model above restricts the current account and real interest rate to be mean-reverting.

Based on my identification of structural shocks, I then test to which extent the simple theoretical model from the first part of the paper holds conditional on a particular type of shock and also to identify dimensions along which the model may fail. For example, one interesting pattern that arises from the earlier analysis is that expected variation in the world interest rate (the 'global' tilting channel) tends to be negatively correlated with the current account, which seems inconsistent with the frictionless model above. The analysis here can help understand which shocks actually account for this finding.

Similar analyses of the present-value model of the current account conditional on a set of structural shocks have been conducted by Nason and Rogers (2002b), Hoffmann (2003, 2001b); Nason and Rogers (2002b) and Kano (2008). Here, I follow the lead of these papers and I suggest a novel, graphical, way of inspecting the cross-equation restrictions imposed by the model: equation (4) should hold also conditionally on any structural shock. By constructing the impulse responses of the channels of external adjustment (expected variation in real interest rates, real exchange rates and net output growth) on the right hand side of (4) and by combining them using the set of estimated structural parameters, it becomes possible to construct a model-implied response of the current account conditional on a specific set of shocks and to compare it with the actually estimated response. My suggestion is to conduct this comparison in a graphical way, i.e. to plot both the response implied by the cross-equation restrictions and the one estimated directly and to check if the former is in the simulated confidence region estimated of the latter. ${ }^{26}$

\footnotetext{
${ }^{26}$ Hoffmann $(2003,2001 b)$, Nason and Rogers (2002b) and Kano (2008) conduct Wald tests on specific subsets of the cross-equation restrictions (e.g. that the impact response of the current account reacts only
} 


\section{Identification of shocks}

The structure of my empirical model allows to separate permanent and transitory components without further identifying restrictions. To see this, note first that the VAR model is essentially a cointegrated system: collect $\Delta \boldsymbol{x}_{t}=\left[\begin{array}{ll}\Delta q_{t} & \Delta n o_{t}\end{array}\right]^{\prime}$ and $\boldsymbol{z}_{t}=\left[\begin{array}{ll}r_{t}^{W} & \frac{C A}{N O} t\end{array}\right]^{\prime}$. Then $X_{t}=\left[\begin{array}{ll}\Delta x_{t} & z_{t}\end{array}\right]^{\prime}$ and the VAR-model from (6) above can be represented as

$$
\left[\begin{array}{c}
\Delta \boldsymbol{x}_{t} \\
\boldsymbol{z}_{t}
\end{array}\right]=\left[\begin{array}{cc}
B_{1}(L) & D_{1}(L) \\
B_{2}(L) & D_{2}(L)
\end{array}\right]\left[\begin{array}{c}
\Delta \boldsymbol{x}_{t-1} \\
\boldsymbol{z}_{t-1}
\end{array}\right]+\boldsymbol{\varepsilon}_{t}
$$

with appropriately partitioned matrix polynomials $B_{1}(L), B_{2}(L), D_{1}(L)$, and $D_{2}(L)$. It is then easily verified that this system can then be rewritten as a vector error correction model with

$$
\Delta X_{t}=\boldsymbol{\Gamma}(\boldsymbol{L}) \Delta X_{t-1}+\boldsymbol{\alpha} \boldsymbol{\beta}^{\prime} X_{t-1}+\varepsilon_{t}
$$

where

$$
\boldsymbol{\Gamma}(L)=\left[\begin{array}{cc}
\boldsymbol{B}_{\mathbf{1}}(L) & \frac{\boldsymbol{D}_{\mathbf{1}}(\boldsymbol{L})-\boldsymbol{D}_{\mathbf{1}}(\mathbf{1})}{1-L} \\
\boldsymbol{B}_{\mathbf{2}}(L) & \frac{\boldsymbol{D}_{\mathbf{2}}(\boldsymbol{L})-\boldsymbol{D}_{\mathbf{2}}(\mathbf{1})}{1-L}
\end{array}\right] \text { and } \boldsymbol{\alpha}=\left[\begin{array}{c}
\boldsymbol{D}_{\mathbf{1}}(1) \\
\boldsymbol{D}_{\mathbf{2}}(1)-\boldsymbol{I}
\end{array}\right]
$$

and where $z_{t}=\boldsymbol{\beta}^{\prime} X_{t}$ is the error-correction term. The matrix $\boldsymbol{\beta}$ stacks the cointegrating vectors, which here are 'trivial' in the sense that they are just the third and fourth unit vectors. ${ }^{27}$

It is well-known that in such a system, the space of permanent and transitory shocks can be directly identified from the adjustment loadings $\alpha$ : in the four-dimensional system here, there are two cointegrating relations, implying that there are two common trends to the transitory part of the response to a net output shock). The approach here provides a convenient graphical way to check whether the cross-equation restriction (5) is satisfied along the entire path of the impulse response of the current account after a shock.

${ }^{27}$ We keep the standard notation in much of the literature on cointegrated models (see e.g. Johansen (1995)) but note that the matrices $\alpha$ and $\beta$ in this subsection are not to be confounded with the scalars $\alpha$ and $\beta$ in the theoretical model above or with the coefficients of the variance decomposition (8). 
(permanent shocks) and two transitory shocks. As shown by Johansen (1995)and as discussed in Hoffmann $(2001 a, b)$, the vector of permanent shocks, $\boldsymbol{\pi}_{t}$, is then identified from

$$
\boldsymbol{\pi}_{t}=\boldsymbol{S}_{p}^{\prime} \boldsymbol{\alpha}_{\perp}^{\prime} \varepsilon_{t}
$$

where $\alpha_{\perp}$ is the orthogonal complement of $\boldsymbol{\alpha}$. Let $\Omega$ denote the covariance matrix of the reduced-form, residuals $\varepsilon_{t}$. Then $\boldsymbol{S}_{p}=\left(\boldsymbol{\alpha}_{\perp}^{\prime} \boldsymbol{\Omega} \boldsymbol{\alpha}_{\perp}\right)^{-1 / 2}$ is a normalization matrix that ensures that the permanent shocks are mutually orthogonal and have unit variance: $\operatorname{var}\left(\boldsymbol{\pi}_{t}\right)=$ $\boldsymbol{I}_{2}$. I will discuss the choice of this matrix shortly. Requiring that transitory shocks are orthogonal to $\pi_{t}$, one obtains

$$
\boldsymbol{\tau}_{t}=\boldsymbol{S}_{\tau}^{\prime} \boldsymbol{\alpha}^{\prime} \Omega^{-1} \varepsilon_{t}
$$

where $\boldsymbol{S}_{\tau}=\left(\boldsymbol{\alpha}^{\prime} \boldsymbol{\Omega}^{-1} \boldsymbol{\alpha}\right)^{1 / 2}$ is again a normalization matrix. The matrices $\boldsymbol{S}_{\pi}$ and $\boldsymbol{S}_{\tau}$ are not uniquely identified. The orthogonality restrictions $\operatorname{var}\left(\boldsymbol{\pi}_{t}\right)=\boldsymbol{I}_{2}$ and $\operatorname{var}\left(\boldsymbol{\tau}_{t}\right)=\boldsymbol{I}_{2}$ impose three non-redundant restrictions on each of them. Therefore, to achieve just-identification, one additional restriction is required for each pair of shocks. I obtain these restrictions by distinguishing between global and a country-specific shock of each type (permanent and transitory). In so doing, I build on Kano (2008) in arguing that only global shocks should have a bearing on the world real rate of interest. To see how this restricts the choice of $\boldsymbol{S}_{p}$ and $\boldsymbol{S}_{\tau}$, note that the relation between the reduced-form residuals and the permanent and transitory shocks can be inverted to obtain

$$
\boldsymbol{\varepsilon}_{t}=\boldsymbol{P}\left[\begin{array}{c}
\tau_{t}^{g} \\
\tau_{t}^{c} \\
\pi_{t}^{g} \\
\pi_{t}
\end{array}\right] .
$$

Here, the superscripts $g$ and $c$ now denote the global and country-specific shocks respec- 
tively and where the matrix $\boldsymbol{P}$ can be shown to be of the form (see Hoffmann (2001a)):

$$
P=\left[\begin{array}{ll}
\alpha S_{\tau}^{-1}, & \Omega \alpha_{\perp}^{\prime} S_{p}^{-1}
\end{array}\right]
$$

The first two columns of $\boldsymbol{P}$ give the period-zero impulse response to the transitory shocks and the last two columns to the permanent shocks. Then recalling the ordering of the variables in our system (the world real interest rate is ordered third), the restrictions on $\boldsymbol{S}_{\tau}$ and $\boldsymbol{S}_{p}$ are given by

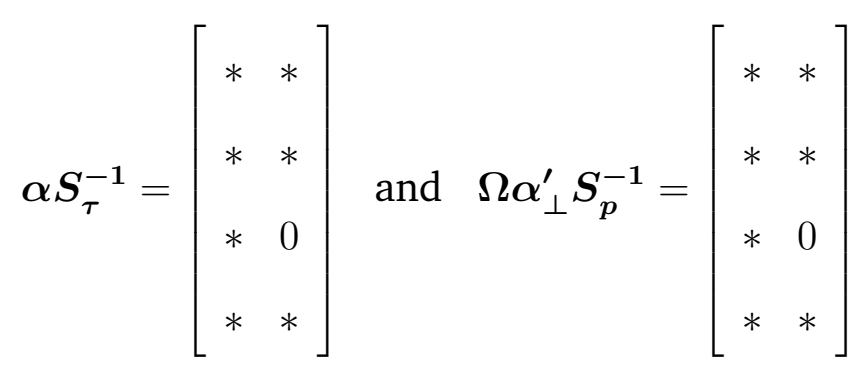

This completes the identification of the shocks.

\section{Impulse responses}

The set of VAR cross-equation restrictions that are imposed by the fundamental current account equation (4) should not only hold unconditionally but also conditionally, for any of the four structural shocks that I have identified above. Given the parameters $b, 1 / \gamma$, and $\alpha$, the current account response to any given shock should equal the sum of the responses on the right hand side of (4). By plotting the predicted and actual current account responses against each other, I therefore obtain an impression to what extent the fundamental current account equation ${ }^{28}$ (4) holds along the dynamic adjustment path of the VAR-model conditional on a shock of a particular type. Figure 6A provides the results of this exercise,

\footnotetext{
${ }^{28}$ This term was coined by Obstfeld and Rogoff (1995)
} 
based on the IFS data for the period 1982-2007. ${ }^{29}$ Interestingly, for all four shocks, the actual current account response lines up with the restrictions imposed by theory: the bootstrapped confidence intervals suggest that the actual response of the current account and the one predicted by the right hand side of (4) are statistically almost indistinguishable. This result lines up with the unconditional findings from the previous sections: there is no single shock with respect to which there would a clear gap between theoretical prediction and actual current account response - the model has considerable fit.

Figures $6 \mathrm{~B}$ and 7 provide more detail on the adjustment of the model to different types of shocks. Figure 6B decomposes the predicted current account response into the individual responses of the two tilting and the smoothing terms (i.e. of the expected discounted sums of future real interest rates, real exchange rate changes and net output growth rates). Figure 6 simply shows the impulse responses of the levels of the four variables in the VAR. The message from both figures is very similar. In particular it is worth zooming in on the role of the permanent global shock, which in small-open economy setting, theoretically, should not have a big impact on the current account. For China, however, this shock leads to a considerable current account surplus by driving up expected future increases in the real exchange rate. In Figure $6 \mathrm{~B}$ this shows up as a huge positive hump of the domestic tilting component of the current account - the sum of expected real exchange rate changes is large and positive on impact and declines thereafter. In Figure 7, we see how these positive changes in the real exchange rate cumulate to a gradual but permanent increase in the real exchange rate. A the same time, both figures show that the permanent global shock is associated with a persistent (though ultimately temporary) decline in the world real interest rate. ${ }^{30}$ The real interest rate response to the permanent

\footnotetext{
${ }^{29}$ In presenting my results, I abstract from the role of the net factor income channel since $b$ is estimated to be so close to zero that multiplying it with the interest rate response is negligible. Note also that results based on the valuation-adjusted current account are very similar.

${ }^{30}$ Based on the valuation-adjusted current account, the permanent global shock also leads to a more sizable expected decrease in net output (results not shown here but available on request). This is consistent with the previous finding that net output variation plays a more important role for current account dynamics once the valuation-adjusted data are used. Interestingly, the interest rate response remains strongly negative also in this setting.
} 
global shock therefore contributes to the negative (unconditional) correlation between the global tilting channel and the current account as it appeared in Table 2 . Clearly, this could be an instance of a 'savings glut'. ${ }^{31}$ It is also worth noting that the global permanent shock contributes to the positive current account response through its negative impact on expected net output changes which gradually cumulate to a decline in national cash flow. This is consistent with our previous finding that growth shocks may be associated with a decline in national cash flow since they predict disproportionate increases in investment. ${ }^{32}$

Table 5 presents variance decompositions of the four variables in the system. First, it is noteworthy that both the permanent and the transitory global shocks together explain most of the variance of the world (US) interest rate at all horizons. This suggests that the identification of global factors works quite well. Note also that the country-specific shock explains most of the transitory variation in the current account. However, permanent shocks — and here in particular the global breed — seem to explain a considerable share of the variation in the current account as well. This suggests that China's current account is to a large extent driven by permanent shocks that are global in the sense that they are also associated with marked swings in the world interest rate. These shocks also seem to account for the patterns of external adjustment that I have established in the first part of the paper. While a more detailed structural interpretation of the global permanent shock is beyond the scope of the analysis here, the responses to it are consistent with the predictions of recent theoretical models that have pointed at the role of China's low domestic financial development for its high savings rate and low global interest rates and

\footnotetext{
${ }^{31}$ It is important to emphasize at this point that the analysis here does not allow me to identify whether the global interest rate variation is not in itself the repercussion of the movement in China's current account, which by itself could be a function of shocks to future domestic non-tradeable prices and national cash flows. What it implies, however, is that large share of the variation in China's current account is associated with global interest rate variation. In fact, this reading would be consistent with the point made by Aizenman and Sun (2010) who argue that, unlike a small open economy, China's size matters for global rebalancing. This is consistent with my results here in that it implies that China will not be able to pursue recent surpluses for a very long period to come.

${ }^{32}$ Note that this result is stronger, once we use the valuation-adjusted data, consistent with our findings in Table 2 where we also found the smoothing channel to play a stronger role in the valuation-adjusted data set.
} 
that I have previously discussed in this paper. ${ }^{33}$

\section{Discussion and Conclusion}

A simple present-value model of the current account explains more than 70 percent of the variation in China's current account over the period 1982-2007 and most of the recent run-up in surpluses. The model nests four channels of external adjustment: net factor income flows, the standard consumption smoothing motive and two forms of consumption tilting: i) tilting due to variation in the world real rate of interest-the global component of tilting - and ii) tilting due to expected changes in the relative price of non-tradeables (i.e. the real exchange rate)—-the domestic component of tilting. My results reveal an important role for the domestic component of tilting and for consumption smoothing. These results hold even once I control for revaluation expectations and measurement error in China's current account. They suggest that expected increases in the price of non-tradeable goods and services such as housing and medical care provide a strong incentive for Chinese households to defer tradeable consumption. My interpretation of the strong showing of the expected variation in national cash flow as a driver of China's current account is that low financial development, capital controls or physical adjustment costs may force firms to finance future investment from retained earnings. In this way, an ultimately positive TFP shock could lead to a persistent (though ultimately temporary) decline in the cash flow available for consumption because investment may be deferred for some while but will then temporarily grow more quickly than output itself.

My taxonomy of the channels of China's external adjustment also reveals a negative correlation between the global tilting component (expected variation in the world interest rate) and the current account. To shed light on this correlation and on external adjustment

\footnotetext{
${ }^{33}$ See Bernanke (2005),Caballero, Farhi and Gourinchas (2008),Mendoza, Quadrini and Rios-Rull (2009), Chamon and Prasad (2010) and Song, Storesletten and Zilibotti (2011) for prominent examples.
} 
more generally, I explore the conditional dynamics of the model by distinguishing between country-specific and global as well as between permanent and transitory shocks.

As a key driver of China's current account (and of the negative correlation with world real interest rates) I identify the permanent global shock: while associated with a decline in the world interest rate, it also leads to a persistent increase in China's current account. At the same time, it also contributes to the strong positive association between the current account and expected price changes for non-tradeables. This pattern is consistent with recent theoretical models in which China's low domestic financial development is a key driver of its surplus and of globally low interest rates.

At a general level, the results in this paper have two major implications: first, China's current account is amenable to modeling using standard econometric tools and does not seem to defy the rules of intertemporal budget balance. To my knowledge, this is the first paper to bring to bear a small —deliberately stylized - model of current account dynamics on the Chinese economy. My analysis suggests that a real appreciation of the currency should be a major factor in external adjustment, a prediction that is vindicated by the recent acceleration in domestic inflation. Also, my model implies that high savings rates predict rising investment rates, consistent with the view that a combination of low financial development and high growth expectations forces private firms to finance future investment from retained earnings.. As China's domestic financial markets develop and as investment rates normalize (which is even more likely in a quickly aging society), there is also likely to be a re-balancing over the medium term (see also Aizenman and Sengupta (2011) for a similar prediction). Secondly the structural analysis shows that re-balancing of China's current account is likely to be associated with global repercussions: much of the variation in China's current account is related to shocks to the world interest rate, which reflects China's increasing weight in the world economy. This again, suggests that China's export-led growth strategy — that a small economy might be able to pursue over very long horizons - will eventually have to come to an end in the medium term (a point 
emphasized by Aizenman and Sun (2010)).

\section{References}

Aguiar, Marc, and Gita Gopinath. 2007. "Emerging Market Business Cycles: The Cycle is the Trend." Journal of Political Economy, 115: 69-102. 4, 6, 27

Aizenman, Joshua, and Rajeswari Sengupta. 2011. "Global Imbalances: Is Germany the New China? A Skeptical View." Open Economies Review, 22(3): 387-400. 35

Aizenman, Joshua, and Yi Sun. 2010. "Globalization and the sustainability of large current account imbalances: Size matters." Journal of Macroeconomics, 32(1): 35-44. 33, 36

Aizenman, Joshua, and Yothin Jinjarak. 2009. "Current account patterns and national real estate markets." Journal of Urban Economics, 66(2): 75-89. 11

Bergin, Paul R, and Steven M Sheffrin. 2000. "Interest Rates, Exchange Rates and Present Value Models of the Current Account." Economic Journal, 110(463): 535-58. 2, 8, 9, 10

Bernanke, Ben S. 2005. "The Global Saving Glut and the U.S. Current Account Deficit." Remarks at the Sandridge Lecture, Virginia Association of Economics, Richmond, Virginia. 34

Blanchard, Olivier Jean, and Danny Quah. 1989. "The Dynamic Effects of Aggregate Demand and Supply Disturbances." American Economic Review, 79(4): 655-73. 27

Bouakez, Hafedh, and Takashi Kano. 2008. "Terms of trade and current account fluctuations: The Harberger-Laursen-Metzler effect revisited." Journal of Macroeconomics, 30(1): 260-281. 10, 12

Caballero, Ricardo J., Emmanuel Farhi, and Pierre-Olivier Gourinchas. 2008. "An Equilibrium Model of Global Imbalances and Low Interest Rates." American Economic Review, 98(1): 358 - 393. $3,5,6,34$

Campbell, John Y., and Robert J. Shiller. 1987. "Cointegration and Present-Value Models." Journal of Political Economy. 18

Chamon, Marcos, and Eswar Prasad. 2010. "Why are Saving Rates of Urban Households in China Rising?" National Bureau of Economic Research 1. 5, 34

Dollar, David, and Aart Kraay. 2006. "Neither a borrower nor a lender: Does China's zero net foreign asset position make economic sense?" Journal of Monetary Economics, 53(5): 943-971. 19 
Engel, Charles, and John H. Rogers. 2006. "The U.S. current account deficit and the expected share of world output." Journal of Monetary Economics, 53(5): 1063-1093. 5, 6,23

Furrer, Tobias. 2011. "Channels of External Adjustment in East Asia before and after the 1997-1998 crisis." Master's diss. University of Zurich. 26

Gete, Pedro. 2010. "Housing Markets and Current Account dynamics." Georgetown University, unpublished Manuscript dated September. 11

Ghosh, A. R. 1995. "International capital mobility amongst the major industrialized countries: Too little or too much?" Economic Journal, 105: 107-128. 12

Glick, Reuven, and Kenneth Rogoff. 1995. "Global versus country-specific productivity shocks and the current account." Journal of Monetary Economics, 35(1): 159-192. 6, 27

Gourinchas, Pierre-Olivier, and Hélène Rey. 2007. "International Financial Adjustment." Journal of Political Economy, 115(4): 665-703. 14, 15

Gourinchas, Pierre-Olivier, and Olivier Jeanne. 2009. "Capital Flows to Developing Countries: The Allocation Puzzle." Peterson Institute for International Economics Peterson Institute Working Paper Series WP09-12. 7, 8, 17

Gruber, Joseph W., and Steven B. Kamin. 2007. "Explaining the global pattern of current account imbalances." Journal of International Money and Finance, 26(4): 500 - 522. 2

Hoffmann, Mathias. 2001a. "Long run recursive VAR models and QR decompositions." Economics Letters, 73(1): 15 - 20. 30, 31

Hoffmann, Mathias. 2001b. "The Relative Dynamics of Investment and the Current Account in the G7-Economies." Economic Journal, 111: C148-163. 6, 27, 28, 30

Hoffmann, Mathias. 2003. "International Macroeconomic Fluctuations and the Current Account." Canadian Journal of Economics, 36(2): 401-420. 27, 28

Iscan, Talan B. 2002. "Present value tests of the current account with durables consumption.” Journal of International Money and Finance, 21(3): 385 - 412. 11

Johansen, Søren. 1995. Likelihood-based inference in cointegrated vector autoregressive models. Oxford:Oxford University Press. ISBN 0-19-8774449-4. 29, 30

Kano, Takashi. 2008. "A structural VAR approach to the intertemporal model of the current account." Journal of International Money and Finance, 27(5): 757-779. 6, 9, 18, 27, 28

Lane, Philip R., and Gian Maria Milesi-Ferretti. 2007. "The External Wealth of Nations Mark II." Journal of International Economics, , (73): 223-250. 3, 13

Mendoza, Enrique G., Vincenzo Quadrini, and Jose-Victor Rios-Rull. 2009. "Financial Integration, Financial Development, and Global Imbalances." Journal of Political Economy, 117(3): 371 - 416. 3, 6, 34 
Nason, James M, and John H Rogers. 2002a. "Investment and the Current Account in the Short Run and the Long Run." Journal of Money, Credit and Banking, 34(4): 967-86. 27

Nason, James M, and John H Rogers. 2002b. "Investment and the Current Account in the Short Run and the Long Run." Journal of Money, Credit and Banking, 34: 967-986. 28

Neumeyer, Pablo A., and Fabrizio Perri. 2005. "Business cycles in emerging economies: the role of interest rates." Journal of Monetary Economics, 52(2): 345 - 380. 4

Obstfeld, Maurice, and Kenneth Rogoff. 1995. Foundations of International Macroeconomics. Princeton University Press. 2, 9, 31

Song, Zheng, Kjetil Storesletten, and Fabrizio Zilibotti. 2011. "Growing like China." American Economic Review, 101: 202-241. 3, 5, 23, 34

Wei, Shang-Jin, and Xiaobo Zhang. 2009. "The Competitive Saving Motive: Evidence from Rising Sex Ratios and Savings Rates in China." National Bureau of Economic Research Working Paper 15093. 5

Yang, Dennis Tao, Junsen Zhang, and Shaojie Zhu. 2010. "Why are Savings Rates so high in China?" Hong Kong Institute for Monetary Research Working Paper 31/2010. 4

Zhang, Zhiwei. 2008. "Dark Matter in China's Current Account." Unpublished manuscript, International Monetary Fund. 3, 14, 16, 21 


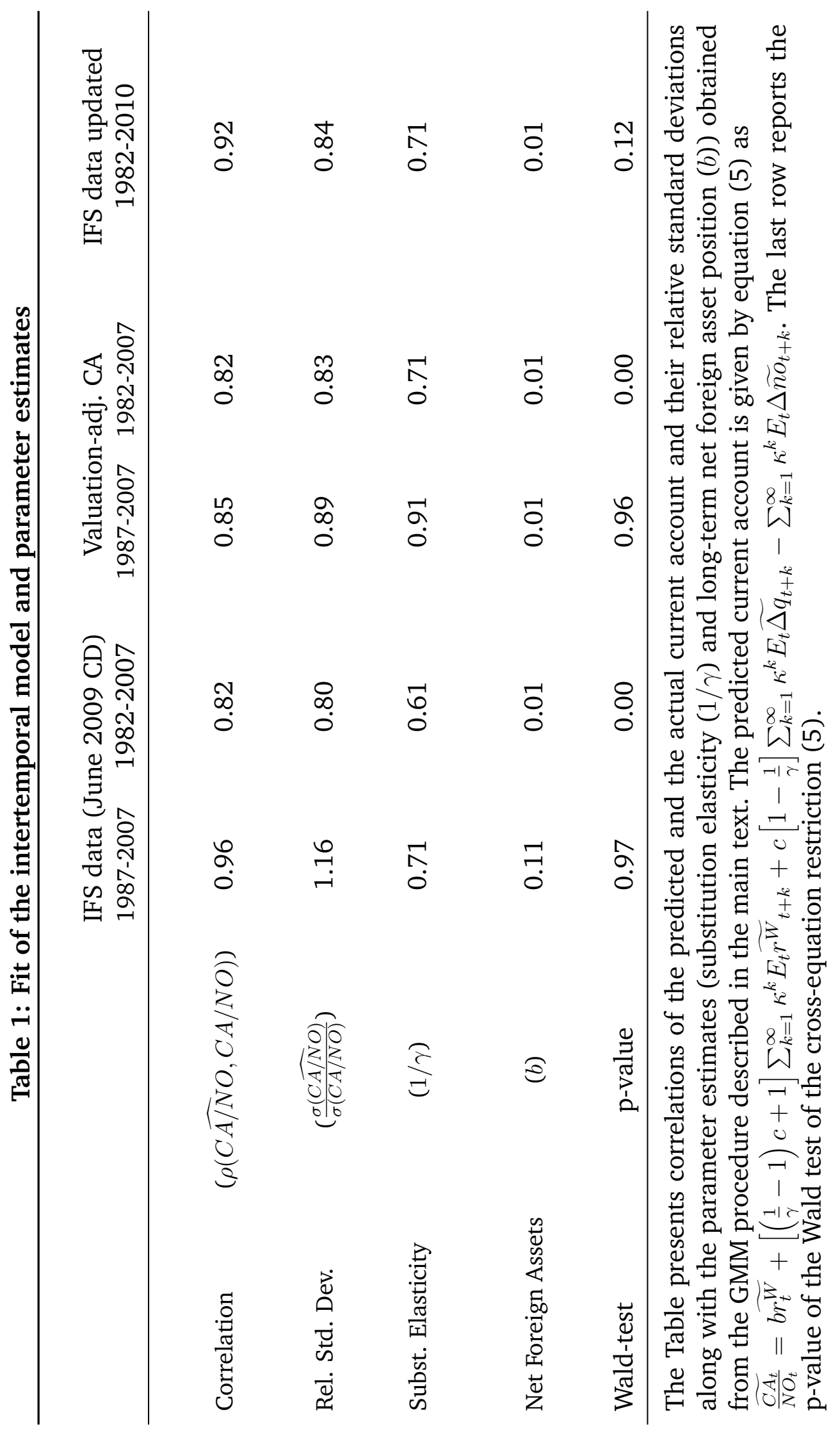




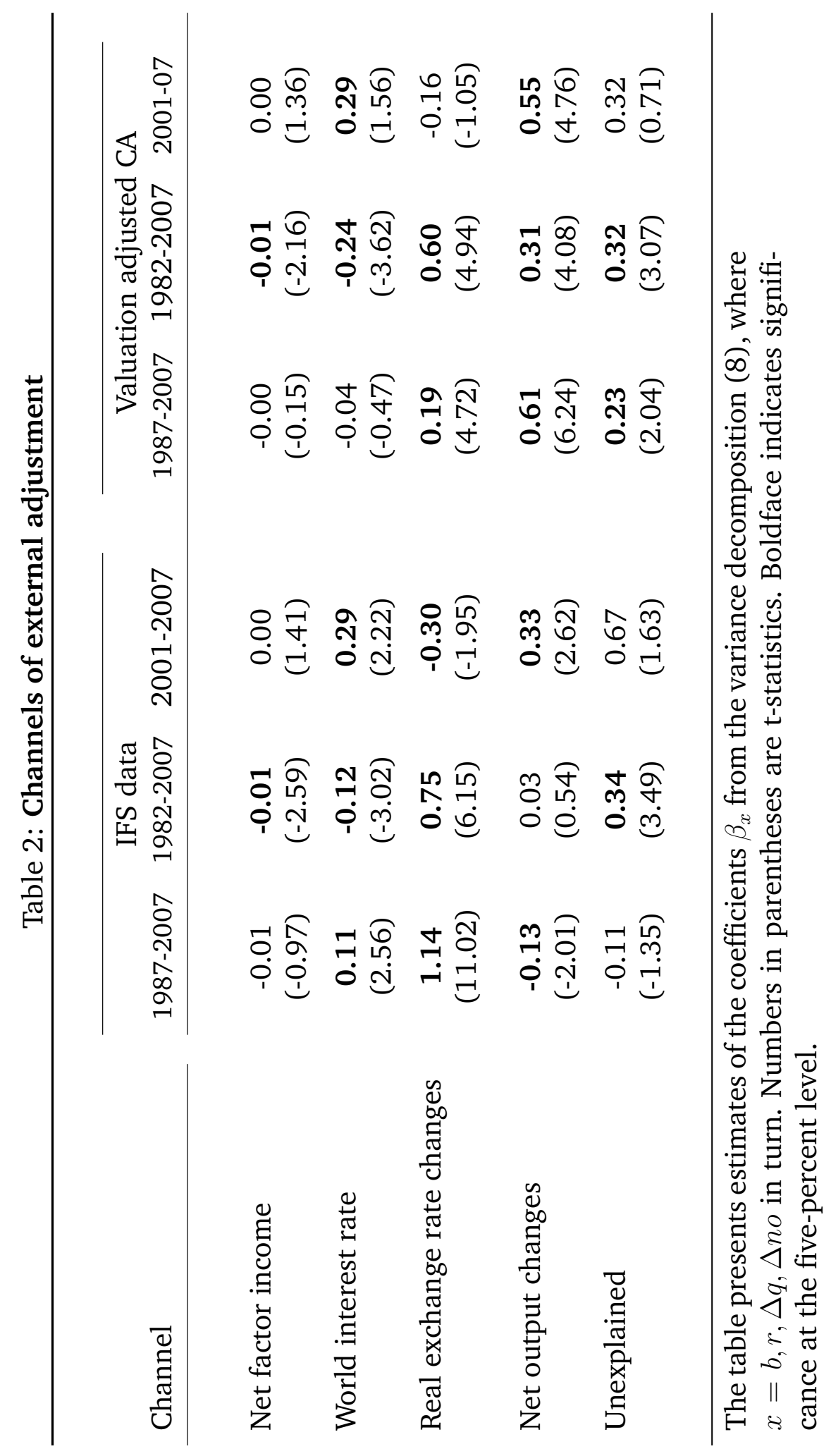


Table 3: Model fit and channels, based on price index of housing and medical care

Val. adjusted CA, 1987-2007

\begin{tabular}{|c|c|c|c|c|}
\hline \multicolumn{2}{|l|}{$\begin{array}{c}\text { Fit of the model } \\
\text { \& parameter estimates }\end{array}$} & \multicolumn{3}{|c|}{ Channels of external adjustment } \\
\hline Correlation & & Net factor income & -0.00 & 0.00 \\
\hline$(\rho(C \widehat{A / N} O, C A / N O))$ & 0.90 & & $(-0.15)$ & $(1.36)$ \\
\hline Rel. Std. Dev. & & World interest rate & -0.04 & 0.05 \\
\hline$\left(\frac{\sigma(C \widehat{A / N} O)}{\sigma(C A / N O)}\right)$ & 0.94 & & $(-1.34)$ & $(1.24)$ \\
\hline Subst. Elasticity & & Real exchange rate & 0.31 & 0.26 \\
\hline$(1 / \gamma)$ & 0.31 & & $(5.65)$ & $(2.11)$ \\
\hline Net Foreign Assets & & Consumption Smoothing & 0.57 & 0.74 \\
\hline$(b)$ & 0.01 & & $(6.14)$ & $(24.01)$ \\
\hline Share of tradeables in CPI & & Unexplained & 0.15 & -0.05 \\
\hline$(\alpha)$ & 0.90 & & $(1.48)$ & $(-0.25)$ \\
\hline \multicolumn{5}{|l|}{ Wald-Test } \\
\hline p-value & 0.99 & & & \\
\hline
\end{tabular}

The left panel of the Table presents correlations and relative standard deviations for predicted and actual current account and the estimated parameters $(1 / \gamma, b$ and $\alpha)$ when the relative price of non-tradeables is measured using an aggregate of prices for housing and medical care. The right panel gives the relative importance of external adjustment channels for this model, based on the decomposition (8). See notes on Tables 1 and 2 for further details. 
Table 4: Channels of external adjustment: out-of-sample stability of the model

In sample: 1982-2001

Out of sample: 1982-2007 based on VAR and parameter estimates 1982-2001 for $1987-2007$

$\begin{array}{lccc}\text { Net factor income } & 0.00 & 0.01 & 0.01 \\ & (-1.06) & (-2.15) & (-2.15) \\ \text { World interest rate } & -\mathbf{0 . 2 7} & -\mathbf{0 . 2 5} & -0.07 \\ & (-4.55) & (-6.04) & (-1.20) \\ \text { Real exchange rate } & \mathbf{0 . 2 8} & \mathbf{0 . 2 8} & \mathbf{0 . 2 2} \\ & (2.34) & (3.95) & (7.40) \\ \text { Consumption Smoothing } & \mathbf{0 . 5 3} & \mathbf{0 . 4 9} & \mathbf{0 . 6 4} \\ & (3.78) & (5.31) & (6.97) \\ \text { Unexplained } & \mathbf{0 . 4 6} & \mathbf{0 . 4 7} & \mathbf{0 . 2 1} \\ & (2.62) & (4.35) & (2.41)\end{array}$

The Table shows the relative importance of external adjustment channels based on the decomposition (8), using valuation-adjusted current account data. The left column shows the in-sample estimate for 1982-2001. The middle and right columns show the decomposition based on the current account predicted for the entire sample period (1982-2007) with the prediction based on the parametrization of the model estimated for 1982-2001 and 19872001 respectively. t-statistics appear in parentheses. 
Table 5: Forecast Error Variance Decompositions 1982-2007

Horizon/yrs

$$
r_{t+k}-E_{t}\left(r_{t+k)} \quad \frac{C A_{t+k}}{N O_{t+k}}-E_{t}\left(\frac{C A_{t+k}}{N O_{t+k}}\right) \quad q_{t+k}-E_{t}\left(q_{t+k}\right) \quad n o_{t+k}-E_{t}\left(n o_{t+k}\right)\right.
$$

global, transitory

$\begin{array}{lllll}1 & 0.64 & 0.09 & 0.16 & 0.10 \\ 3 & 0.56 & 0.05 & 0.15 & 0.07 \\ 5 & 0.42 & 0.04 & 0.07 & 0.03\end{array}$

$[0.14-0.56] \quad[0.02-0.22] \quad[0.02-0.14] \quad[0.02-0.14]$

country-spec., trans.

$\begin{array}{lllll}1 & 0.00 & 0.40 & 0.22 & 0.01 \\ 3 & 0.00 & 0.53 & 0.15 & 0.01 \\ 5 & 0.01 & 0.30 & 0.04 & 0.01\end{array}$

$[0.01-0.14]$

[0.07-0.39]

[0.01-0.14]

[0.01-0.08]

global permanent

$\begin{array}{ccccc}1 & 0.36 & 0.02 & 0.52 & 0.07 \\ 3 & 0.42 & 0.16 & 0.30 & 0.13 \\ 5 & 0.45 & 0.51 & 0.32 & 0.15 \\ & {[0.13-0.67]} & {[0.09-0.64]} & {[0.08-0.73]} & {[0.03-0.82]}\end{array}$

country-spec., permanent

$\begin{array}{ccccc}1 & 0.00 & 0.49 & 0.09 & 0.82 \\ 3 & 0.02 & 0.26 & 0.40 & 0.79 \\ 5 & 0.11 & 0.14 & 0.57 & 0.81 \\ & {[0.04-0.35]} & {[0.08-0.53]} & {[0.13-0.81]} & {[0.09-0.91]}\end{array}$

Table presents forecast error variance decompositions based on IFS data for the 1982-2007 period. Numbers in rectangular brackets indicate 80 percent bootstrap confidence intervals at the 5-year horizon. 

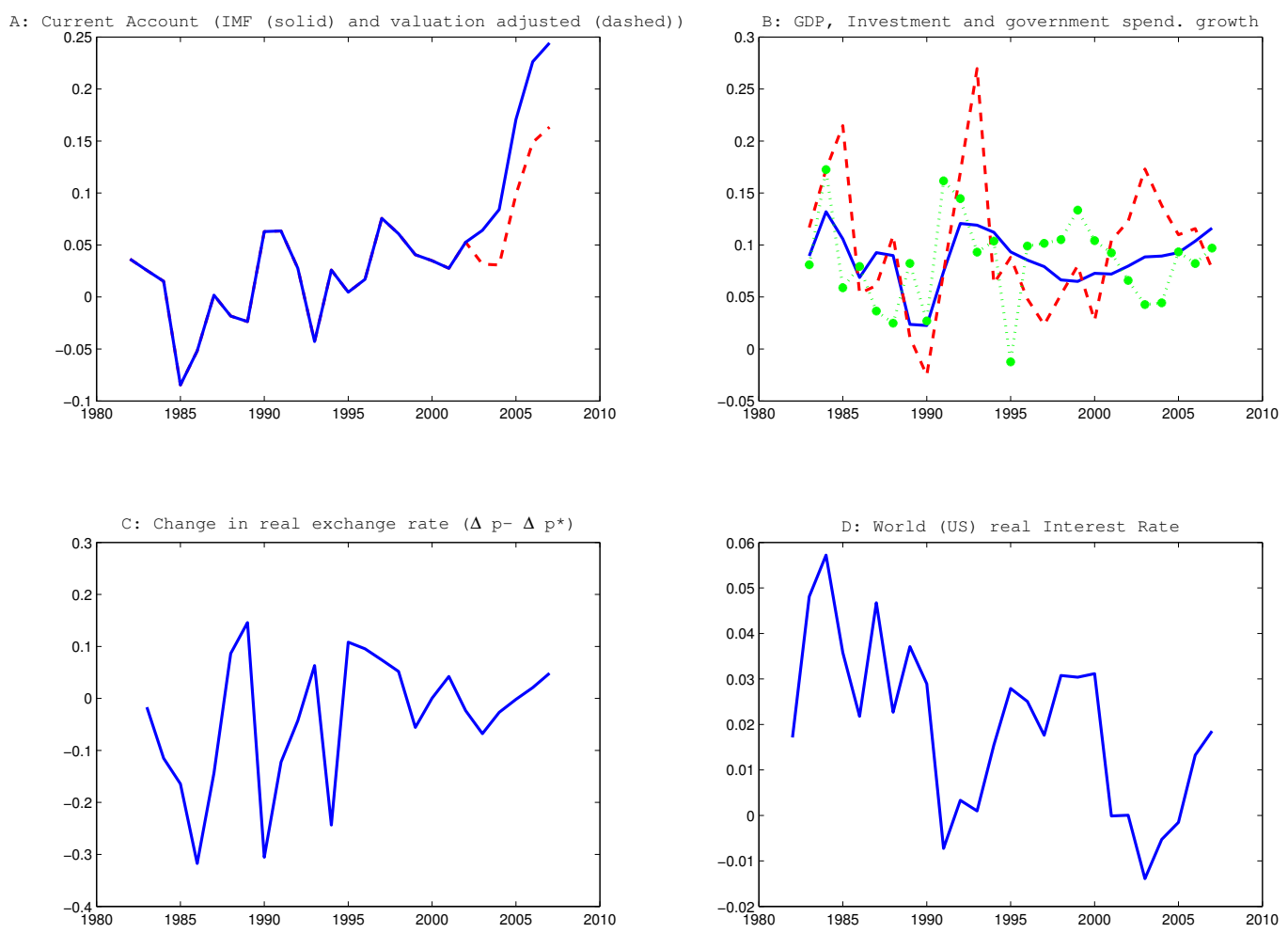

FIGURE 1: Plot of the main data used in the analysis. Panel A:current account over net output. The red-dashed line represents Zhangs (2008) valuation-adjusted current account data (after 2003). Panel B: output (solid line)), investment (red dashed line) and government spending growth rates (green, dotted line). Panel C: the rate of change of the real exchange rate. Panel D: the world (US) real interest rate (lower left). 
Panel I

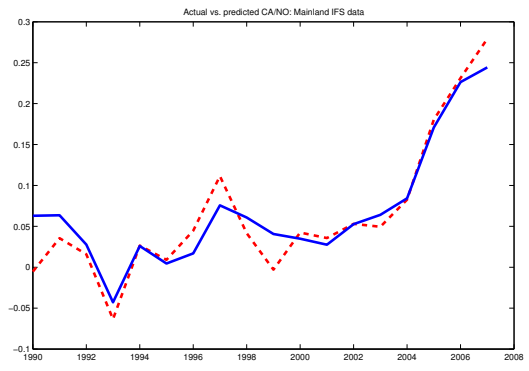

Panel III

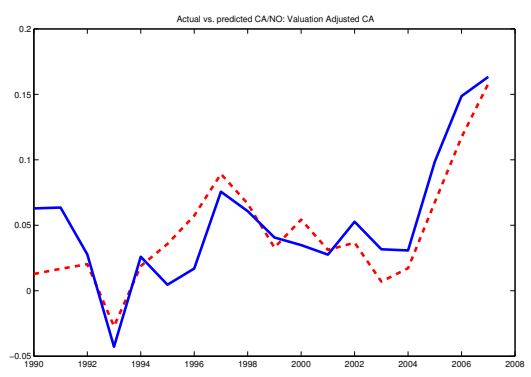

Panel II

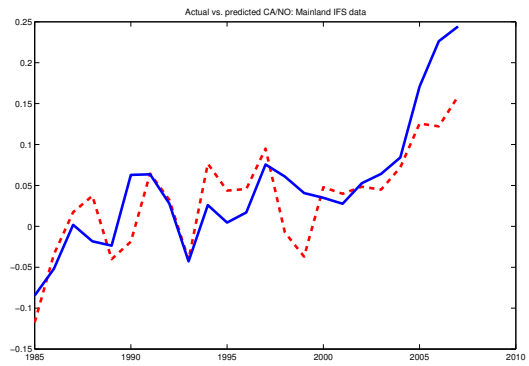

Panel IV

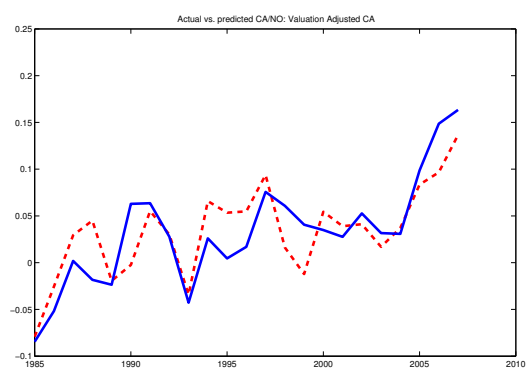

FIGURE 2A: Actual Current account over net output ratio $(C A / N O)$ (blue, solid line) vs.model prediction (red, dashed line). The left column (panel A and C) shows the results for the 1987-2007 period, the right column (panel B and D) for the 1982-2007 period. The results in panel I and II are obtained from the model estimated from the official IFS statistics, the ones on panels III and IV from the valuation adjusted current account.

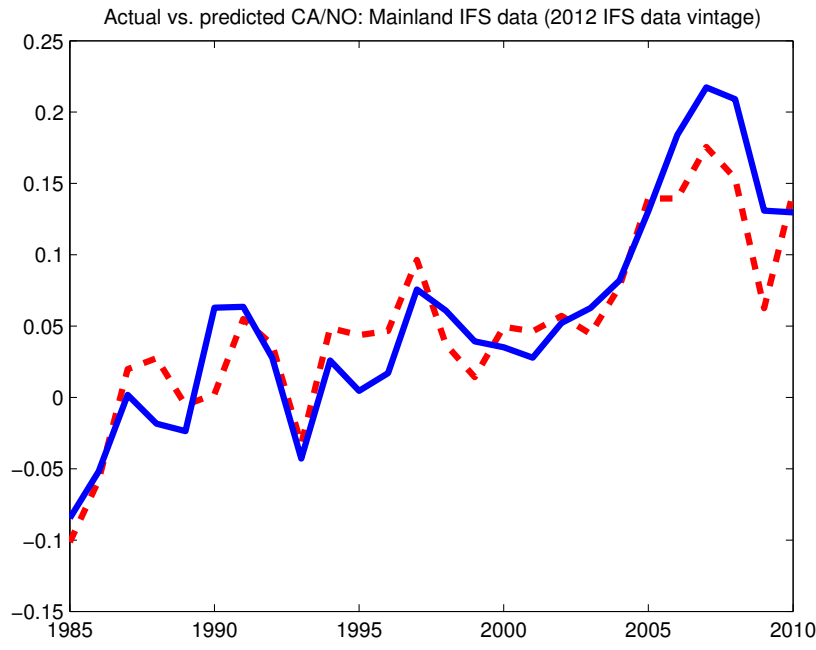

FIGURE 2B: Actual Current account over net output ratio $(C A / N O)$ (blue, solid line) vs.model prediction (red, dashed line) based on the updated (May 2012) IFS data set, ranging from 1982-2010. 

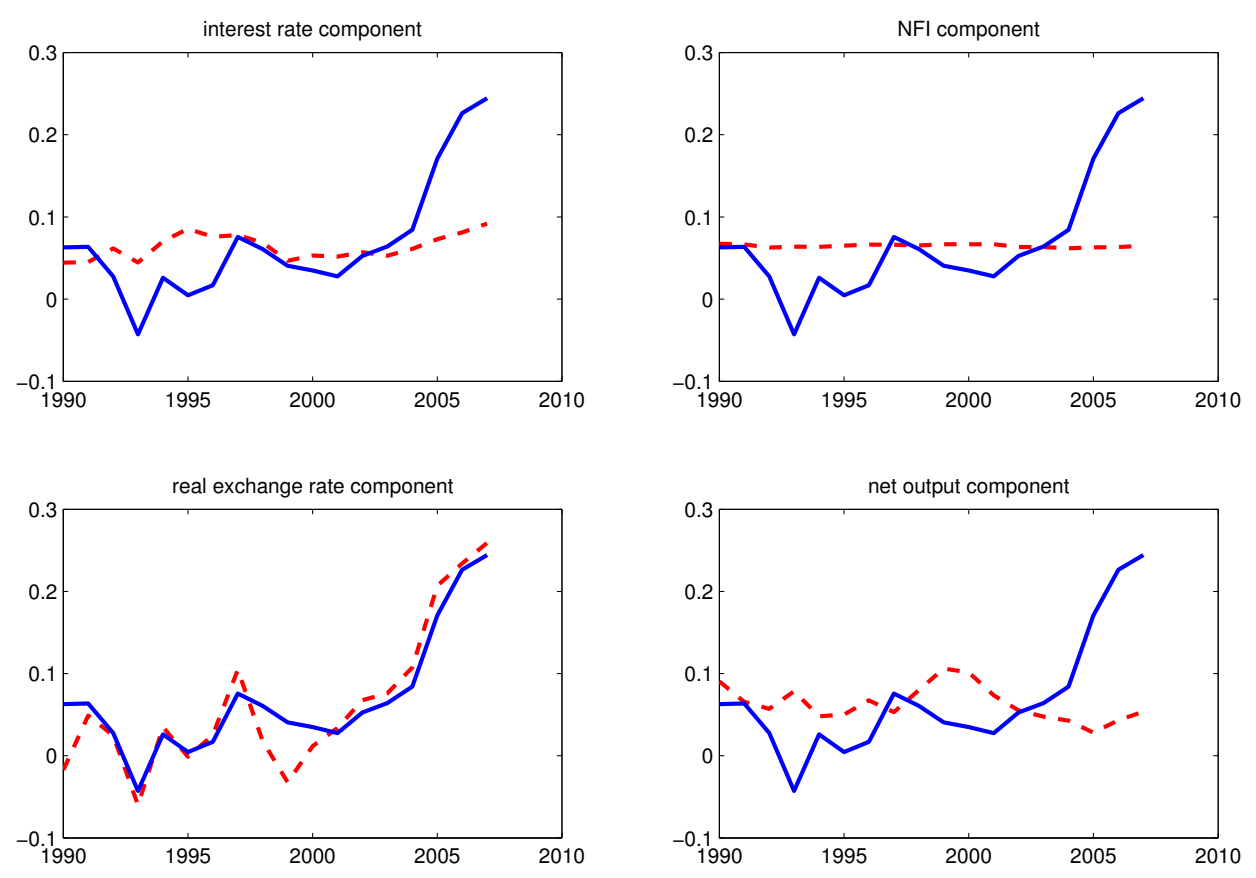

FIGURE 3A: Current Account / Net output ratio (IFS data) (blue, solid line) vs. individual channel components extracted from the model (red, dashed line).
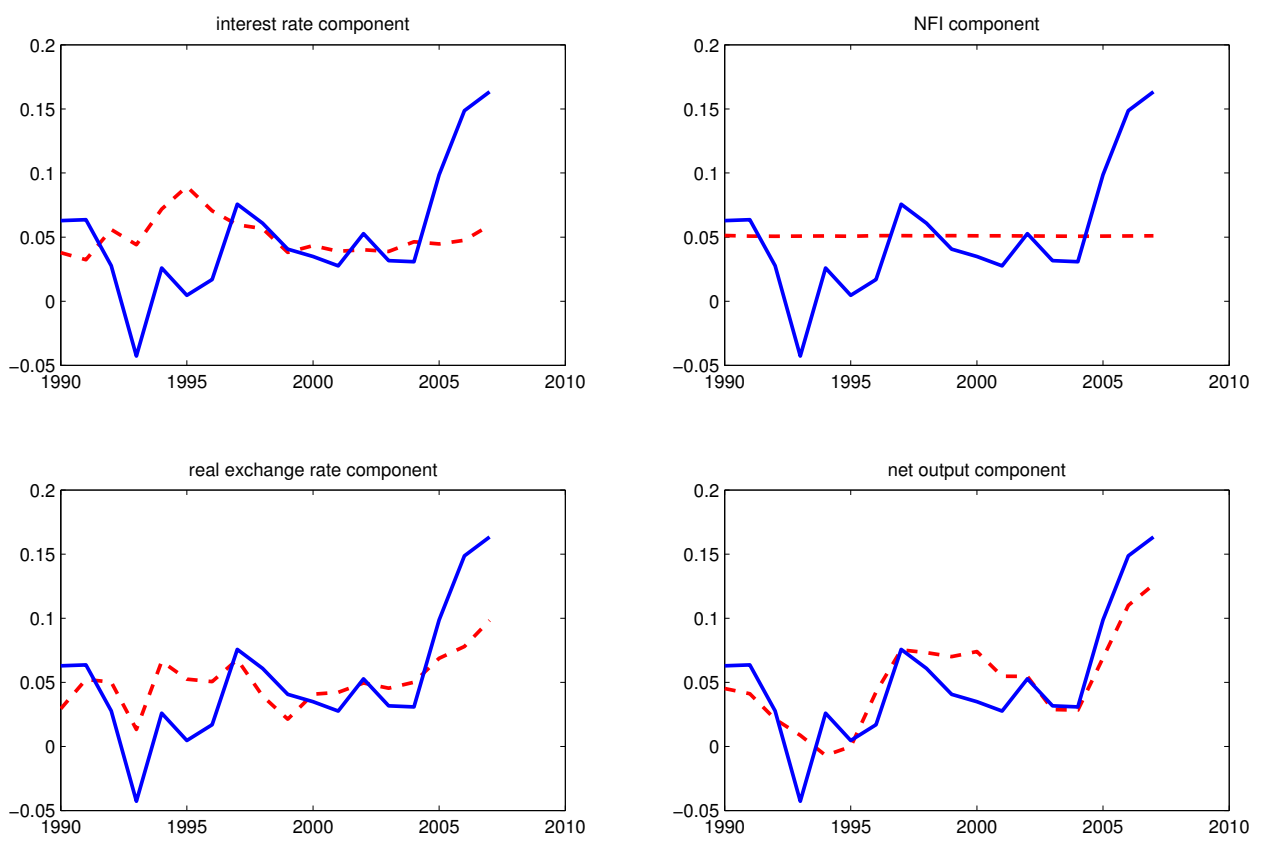

FIGURE 3B: Current Account / Net output ratio (valuation adjusted data) (blue, solid line) vs. individual channel components extracted from the model (red, dashed line). 

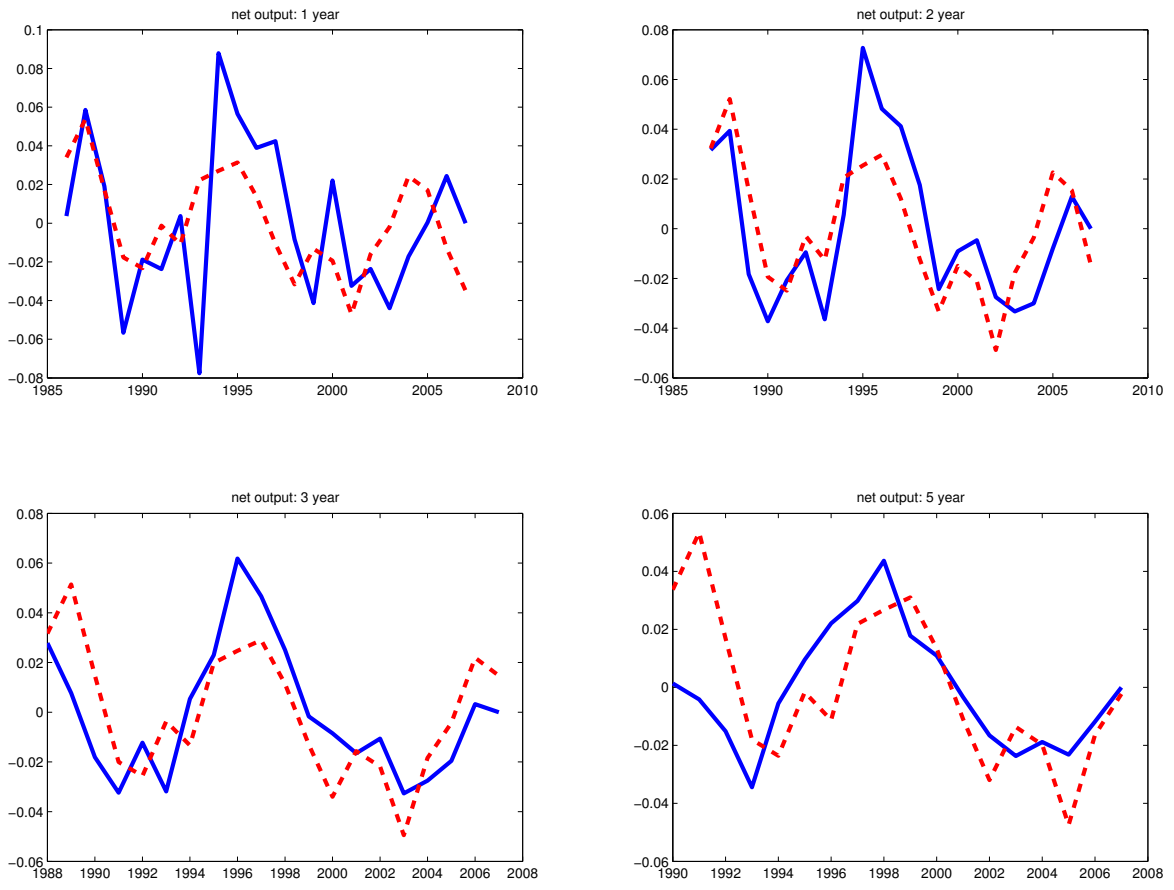

FIGURE 4A: Net output growth rates over 1,2,3,5 years (blue, solid line) vs. the VAR-implied long-run predictions (red, dashed) line. Valuation-adjusted data, 1982-2007.
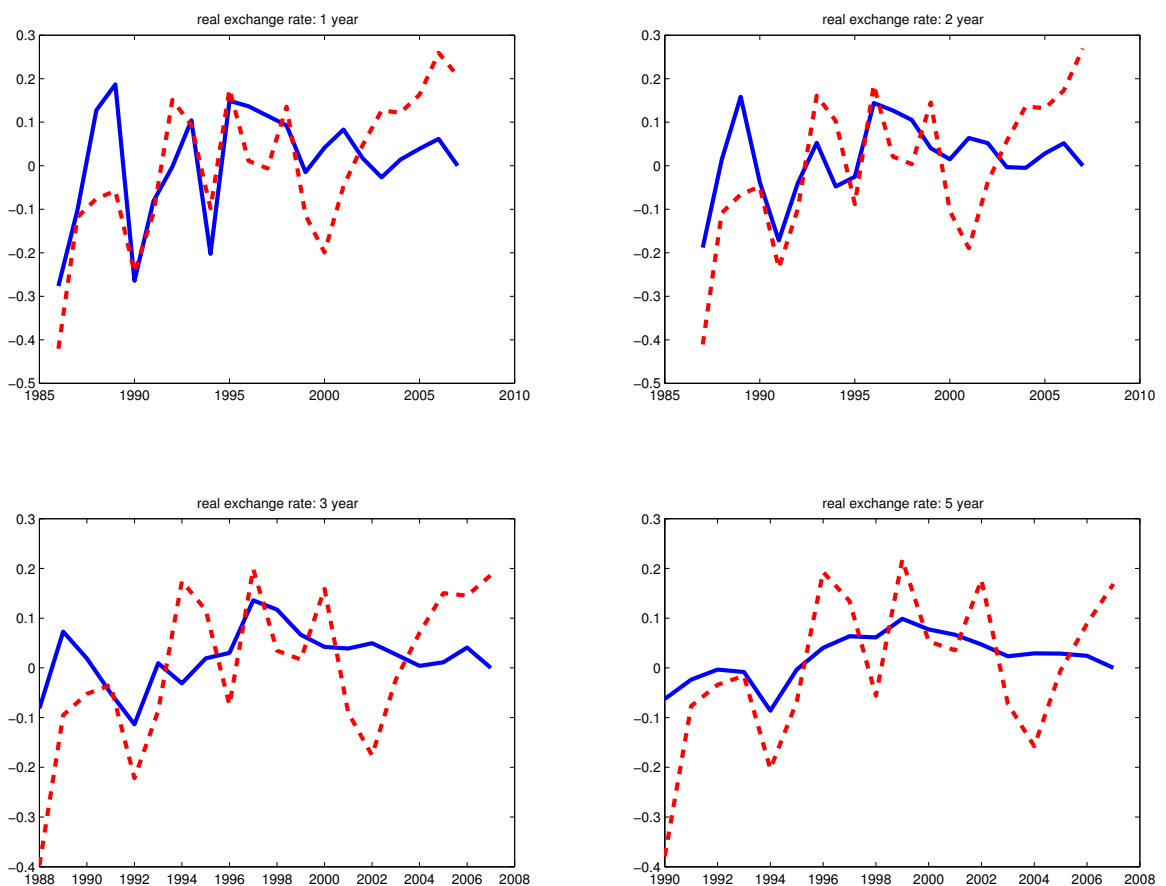

FIGURE 4B: Real exchange rate changes ober 1,2,3,5 years (blue, solid line) vs. the VAR-implied long-run predictions (red, dashed lines). Valuation-adjusted data, 1982-2007. 


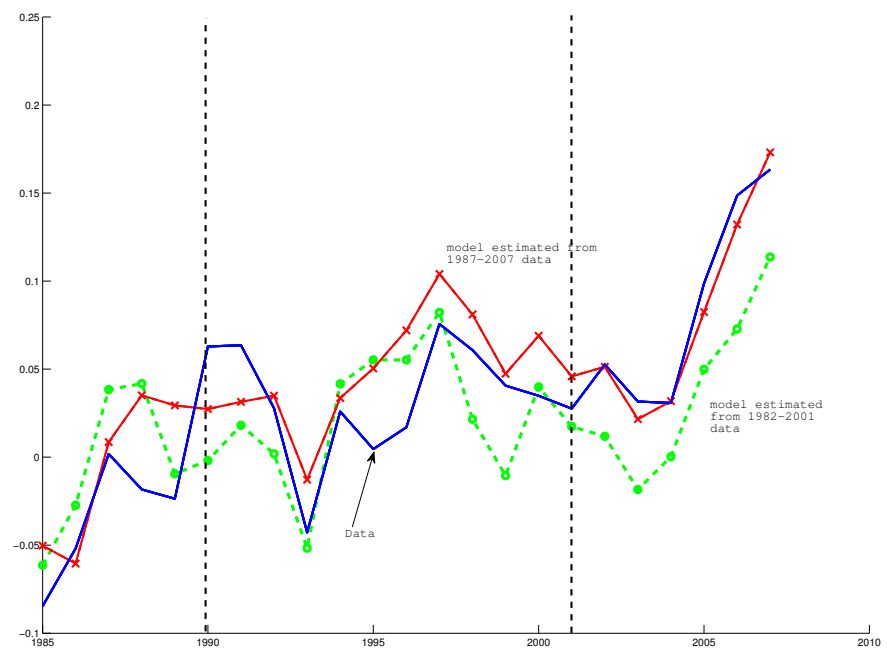

FIGURE 5A: current account predicted for 1982-2007 from the model based on VAR and parameter estimates for different subperiods: 1982-2001 (green dashed line with dots) and 1987-2007 (red, solid line with crosses). The current account based on valuationadjusted data appears as blue (solid) line. Vertical lines indicate the years 1990 and 2001 before (after) which the values from the 1987-2001 (1982-2001) models are back- (fore-) casted respectively.

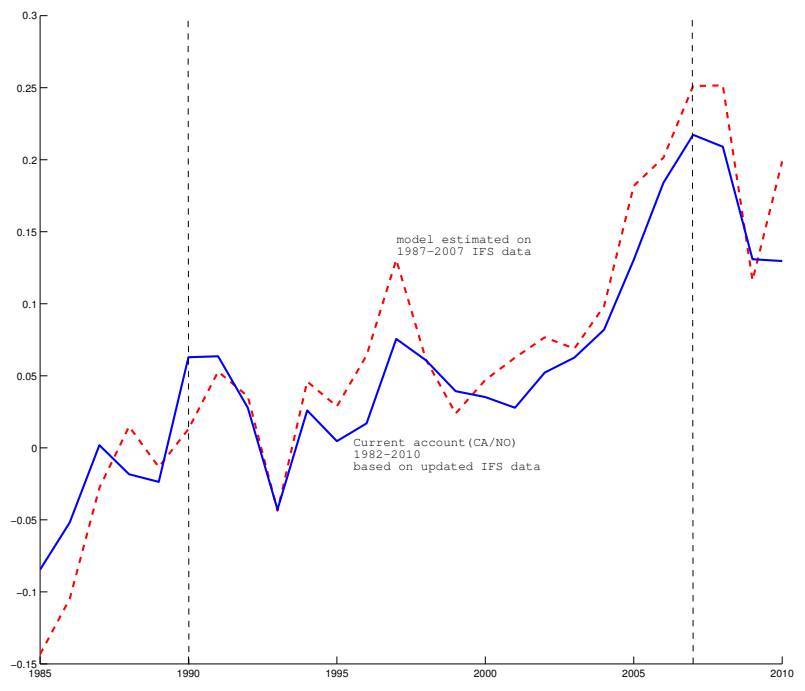

FIGURE 5B: The blue (solid) line is the current account $(C A / N O)$ calculated based on an updated data set (1982-2010) from the May 2012 issue of the IFS CD-ROM. The red (dashed) line is the fitted current account obtained using the updated (May 2012) data set, using the model parametrization estimated from the baseline data set over the sample period 1987-2007. 

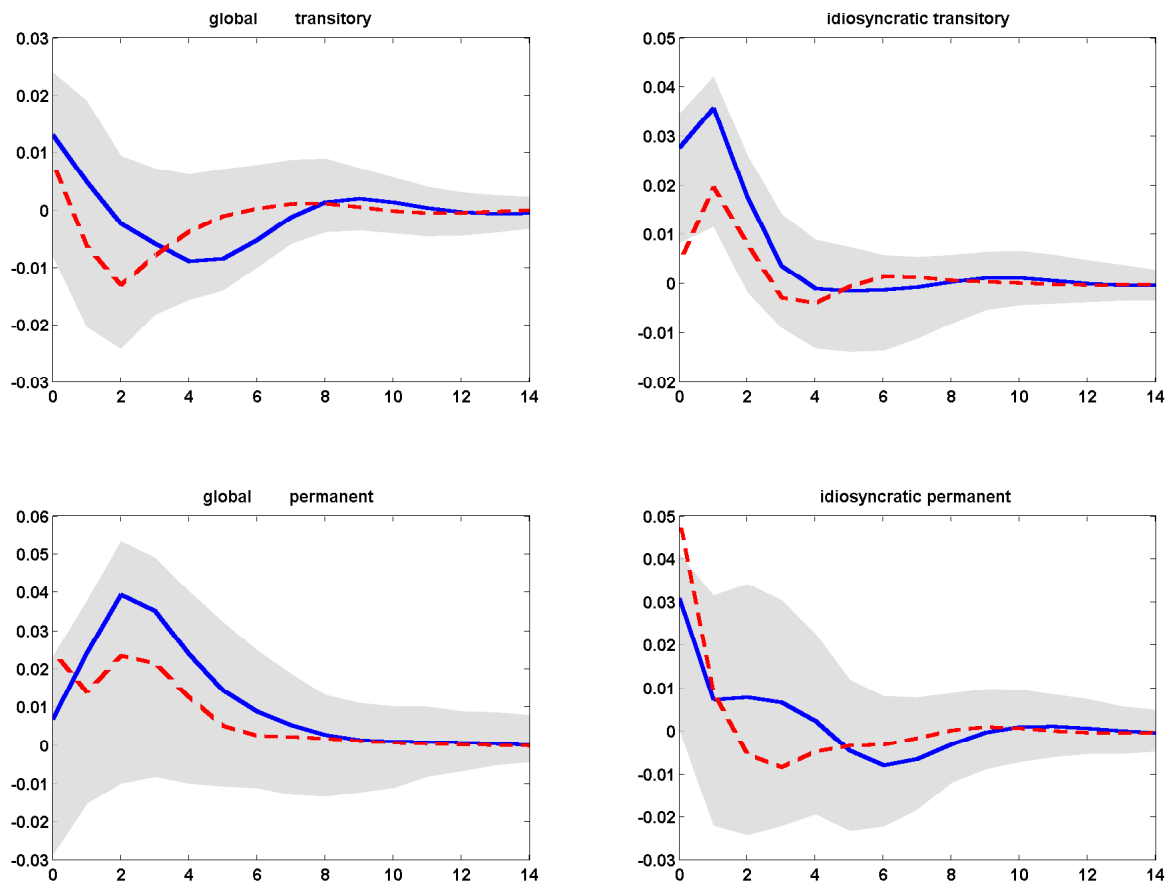

FIGURE 6A: Impulse response of the current account: actual (blue, solid line) vs. theoretically predicted (red, dashed) line. IFS data, 19822007. Shaded areas indicate 80-percent bootstrapped confidence interval of the actual response.
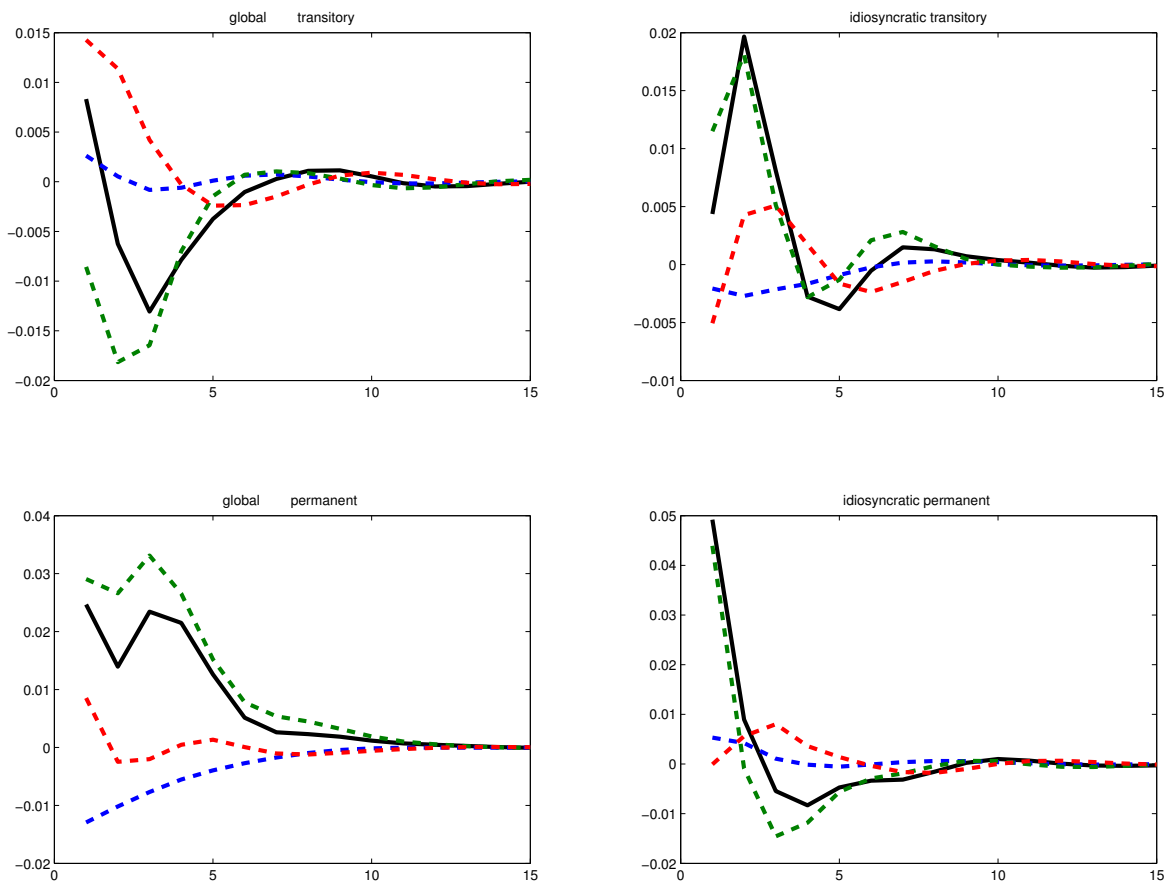

FIGURE 6B: Response of the theoretically predicted current account (black, solid line) and decomposition into the impulse response of the individual channels (dashed lines): consumption tilting due to world real interest rate (blue) and real exchange rate (olive) changes and consumption smoothing due to net output changes (red). IFS data, 19822007. 


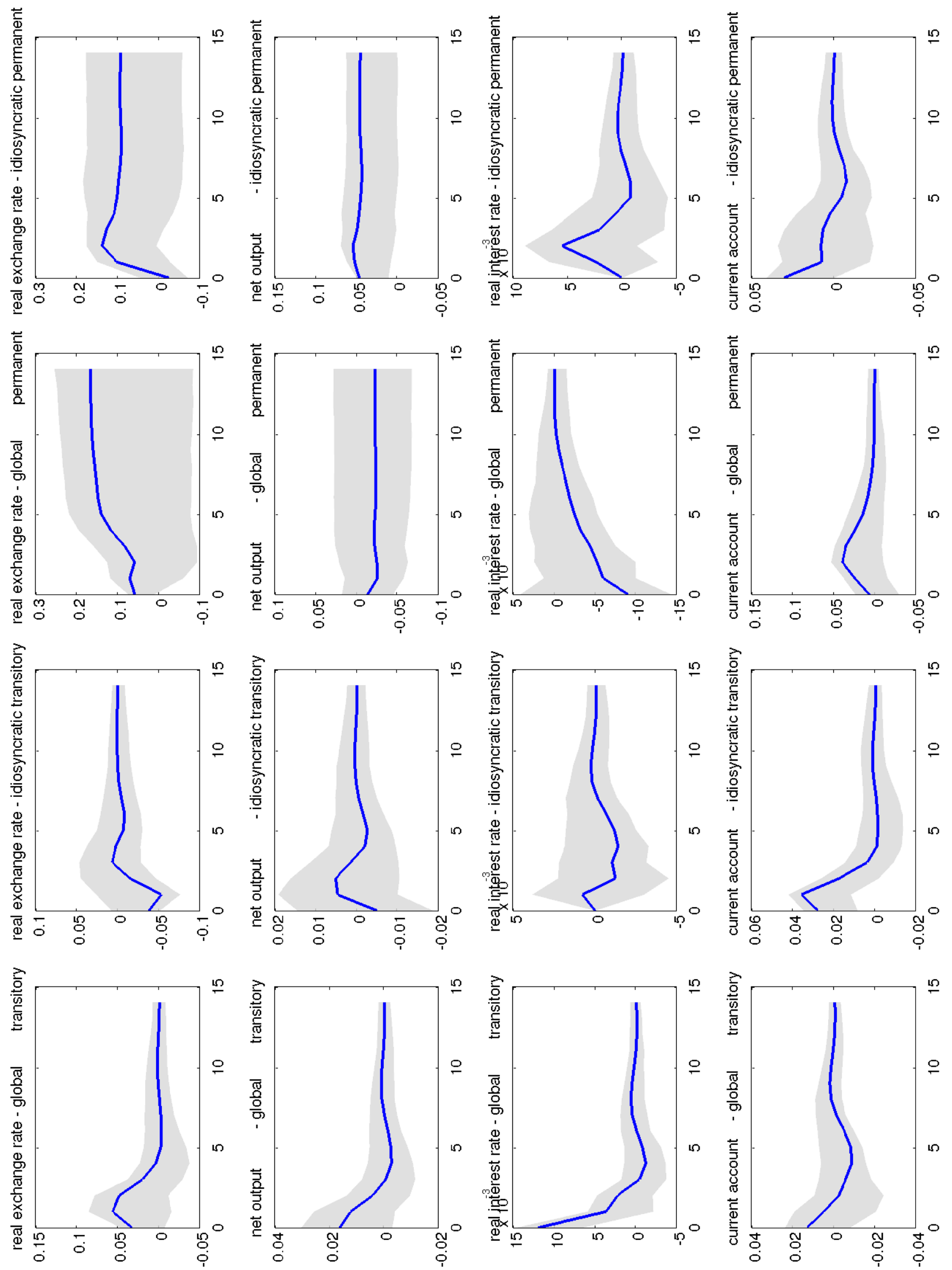

- 